\title{
O PAPEL DA EDUCAÇÃO NO DESENVOLVIMENTO COMO LIBERDADE: UMA ANÁLISE COMPARADA DE FINLÂNDIA E COREIA DO SUL ${ }^{1,2}$
}

Fábio Domingues Waltenberg ${ }^{3}$

Fernanda Scarparo Martins ${ }^{4}$

Adotando como referência a abordagem de desenvolvimento como liberdade, de Amartya Sen, comparam-se Finlândia e Coreia do Sul, dois países que priorizaram investimentos em educação ao longo de décadas, período que coincidiu com um grande salto em seu nível de desenvolvimento. Embora ambos os países tenham sido capazes de erguer sistemas de educação considerados de alto padrão, apoiaram-se em princípios absolutamente diferentes para atingilos. Analisam-se as motivações para os maciços investimentos educacionais na Coreia do Sul e na Finlândia e se apresenta a configuração atual dos seus sistemas educacionais, com alguns elementos de sua evolução histórica. Procura-se, então, avaliar em que medida os sistemas educacionais desencadeiam consequências mais amplas do que resultados em provas de proficiência - efeitos desejáveis ou não dentro da perspectiva de desenvolvimento adotada. Para isto, recorre-se a indicadores de qualidade de vida dos alunos, extraídos da edição de 2015 do Programa Internacional de Avaliação de Alunos (em inglês, Programme for International Student Assessment - Pisa), bem como àqueles de percepção de qualidade da sociedade, oriundos do Programa para Avaliação Internacional de Competências de Adultos (em inglês, Programme for the International Assessment of Adult Competencies - PIAAC), de 2011-2012. Conclui-se que 0 sistema educacional finlandês está mais afinado ao conceito de desenvolvimento como liberdade.

Palavras-chave: Amartya Sen; desenvolvimento como liberdade; educação; Finlândia; Coreia do Sul.

\section{THE ROLE OF EDUCATION IN DEVELOPMENT AS FREEDOM: A COMPARED ANALYSIS OF FINLAND AND SOUTH KOREA}

Adopting as a benchmark Amartya Sen's concept of development as freedom, we compare Finland and South Korea, two countries that gave priority to investments in education for decades, which coincided with a major improvement in their development level. While both countries have been capable of raising world-class educational systems, the principles which guided each country were opposed. We analyze the motivations for South Korea and Finland to invest massively in education, and we present the current configuration of their educational systems, with some elements of their historical evolution. Then we evaluate to what extent the educational systems trigger consequences beyond proficiency exams desirable or not according to a given concept of development. To this end, we employ indicators of students' quality of life, extracted from the Programme for International Student Assessment (Pisa) 2015 edition, as well as indicators of perceptions of quality of society, coming from the Programme for the

1. DOI: http://dx.doi.org/10.38116/ppp56art10

2. Por suas críticas, comentários e sugestões, os autores gostariam de agradecer aos professores Celia Kerstenetzky e Francisco Duarte, bem como a Eunae Baek, estudante sul-coreana atualmente matriculada na Universidade Federal Fluminense (UFF), por sua leitura crítica das seções que tratam da Coreia do Sul, e pelas sugestões de referências complementares a respeito daquele país.

3. Professor associado do Departamento de Economia da UFF. Pesquisador do Centro de Estudos sobre Desigualdade e Desenvolvimento (CEDE). E-mail: <fdwaltenberg@id.uff.br>.

4. Mestre em economia pela UFF. E-mail:<fernanda_scarparo@yahoo.com.br>. 
International Assessment of Adult Competencies (PIAAC) 2011-2012. We conclude that the Finnish educational system is more in tune with the concept of development as freedom.

Keywords: Amartya Sen; development as freedom; education; Finland; South Korea.

\section{EL PAPEL DE LA EDUCACIÓN EN EL DESARROLLO COMO LIBERTAD: UN ANÁLISIS COMPARADO DE FINLANDIA Y COREA DEL SUR}

Adoptando como referencia el enfoque de desarrollo como libertad de Amartya Sen, se comparan Finlandia y Corea del Sur, dos países que priorizaron inversiones en educación a lo largo de décadas, período que coincidió con un gran salto en su nivel de desarrollo. Aunque ambos países han sido capaces de erigir sistemas de educación considerados de alto nivel, se apoyaron en principios absolutamente diferentes para alcanzarlo. Se analizan las motivaciones para las masivas inversiones educativas en Corea del Sur y en Finlandia y se presenta la configuración actual de sus sistemas educativos, con algunos elementos de su evolución histórica. Se busca entonces evaluar en qué medida los sistemas educativos desencadenan consecuencias más amplias que resultados en pruebas de proficiencia - efectos deseables o no dentro de la perspectiva de desarrollo adoptada. Para ello, se recurre a indicadores de calidad de vida de los alumnos, extraídos de la edición 2015 del Programme for International Student Assessment (Pisa), así como a aquellos de percepción de calidad de la sociedad, oriundos del International Assessment of Adult Competencies (PIAAC) de 2011-2012. Se concluye que el sistema educativo finlandés está más afinado al concepto de desarrollo como libertad.

Palabras clave: Amartya Sen; desarrollo como libertad; educación; Finlandia; Corea del Sur.

\section{LE RÔLE DE L'ÉDUCATION DANS LE DÉVELOPPEMENT COMME LIBERTÉ: UNE ANALYSE COMPARÉE DE LA FINLANDE ET DE LA CORÉE DU SUD}

Adoptant comme référence l'approche d'Amartya Sen de développement comme liberté, nous comparons la Finlande et la Corée du Sud, deux pays qui ont privilégié l'investissement dans l'éducation pendant des décennies, ce qui a coïncidé avec un grand bond en avant dans leur niveau de développement. Alors que les deux pays ont été en mesure d'ériger des systèmes éducatifs considérés comme étant de très haut niveau, ils se sont appuyés sur des principes absolument différents pour y parvenir. Les motivations pour les investissements éducatifs massifs en Corée du Sud et en Finlande sont analysées et la configuration actuelle de leurs systèmes éducatifs est présentée, ainsi que quelques éléments de leur évolution historique. Nous cherchons ensuite à évaluer dans quelle mesure les systèmes éducatifs entraînent des conséquences plus larges que les résultats dans des tests de competence des élèves effets souhaitables ou non, selon le concept de développement adopté. Pour cela, nous utilisons des indicateurs de qualité de vie des étudiants, extraits de l'édition 2015 de Programme for International Student Assessment (Pisa), ainsi que ceux de perception de la qualité de la société, issus du International Assessment of Adult Competencies (PIAAC) de 2011-2012. Nous concluons que le système éducatif finlandais est plus adapté au concept de développement comme liberté.

Mots-clés: Amartya Sen; développement comme liberté; education; Finlande; Corée du Sud.

JEL: I250; I260; I280; 0150; 0570.

\section{INTRODUÇÃO}

No debate sobre desenvolvimento, é comum recorrer-se à observação de experiências bem-sucedidas de países que foram capazes de mudar de patamar e, de certa forma, ultrapassar a barreira do subdesenvolvimento. Com as devidas ressalvas e 
cautelas na adaptação a contextos nacionais e a momentos históricos diferentes, seria possível extrair liçóes dessas experiências, a fim de, eventualmente, formular-se recomendações de políticas públicas.

O conceito de desenvolvimento evoluiu ao longo dos anos. Partindo de ser quase sinônimo de crescimento econômico, hoje é entendido de forma mais abrangente. Amartya Sen foi um dos autores que destacaram a necessidade de integrar outras esferas, como social e política, na análise do processo de desenvolvimento. Com uma proposta inovadora, estabeleceu a qualidade de vida e a liberdade das pessoas como fins do desenvolvimento.

São diversas as virtudes da educação, não apenas sua instrumental correlação positiva, em nível individual - com retornos monetários, bem-estar individual e expansão da cidadania - ou em nível coletivo, com crescimento econômico, redução de desigualdades, promoção de coesão social etc. Mas também sua importância intrínseca, no sentido de constituir em si mesma uma manifestação do desenvolvimento de uma nação.

Países que utilizaram políticas de educação intensamente em suas estratégias de desenvolvimento por vezes são apontados como modelos. Finlândia e Coreia do Sul seriam exemplos de como uma sociedade poderia usar o conhecimento a seu favor no objetivo de tornar-se mais avançada e, por isso, tornaram-se referências. Pouco se conhece no Brasil, contudo, sobre a relação entre processos de desenvolvimento e a evolução das políticas de educação desses países.

A metodologia adotada neste artigo consistiu em fixar como referência conceitual a abordagem de "desenvolvimento como liberdade", de Amartya Sen, e em observar de forma comparada Finlândia e Coreia do Sul, dois países que priorizaram investimentos em educação ao longo de décadas, período que coincidiu com um grande salto em seu nível de desenvolvimento. Embora ambos os países tenham sido capazes de erguer sistemas de educação considerados de alto padrão - o que se reflete, por exemplo, em altas taxas de matrícula nos diversos níveis de ensino, além do desempenho elevado em avaliaçóes como os exames do Programa Internacional de Avaliação de Alunos (em inglês, Programme for International Student Assessment-Pisa) ${ }^{5}$ - apoiaram-se em princípios absolutamente diferentes entre si para atingir tais objetivos, o que os levou a seguir caminhos muito distintos em suas políticas educacionais. Do contraste entre essas trajetórias diferentes, espera-se que se possam extrair liçóes mais consistentes do que se poderia alcançar caso apenas um dos países fosse objeto de atenção. 
Depois de uma síntese do papel da educação na concepção de Sen de desenvolvimento como liberdade (seção 2), analisam-se as motivaçóes para os maciços investimentos educacionais na Coreia do Sul e na Finlândia e se apresenta a configuraçáo atual dos seus sistemas educacionais, com alguns elementos de sua evolução histórica (seçóes 3 a 6). Procura-se, então, avaliar em que medida os sistemas educacionais desencadeiam consequências mais amplas do que resultados em provas de proficiência - efeitos desejáveis ou não dentro da perspectiva de desenvolvimento de Amartya Sen. Para isto, apresentam-se indicadores de qualidade de vida dos alunos, extraídos da edição 2015 do Pisa (seção 7), bem como indicadores de percepçâo de qualidade da sociedade oriundos do Programa para Avaliação Internacional de Competências de Adultos (em inglês, Programme for the International Assessment of Adult Competencies - PIAAC) $)^{6}$ - seção 8 . A seção 9 contém consideraçóes finais, fechando o artigo, com a conclusão principal de que o sistema educacional finlandês está mais afinado ao conceito de desenvolvimento como liberdade.

\section{EDUCAÇÃO NO DESENVOLVIMENTO COMO LIBERDADE}

No último quartel do século passado, diante de novos e velhos desafios, proliferam novas abordagens teórico-conceituais no campo do desenvolvimento, segundo Hirschman (1981). Para muitos, ${ }^{7}$ o conceito de desenvolvimento passa a englobar não somente aspectos econômicos, mas também sociais, territoriais, ambientais, entre outros.

Nesse quadro de pulverização, Sen (2010) destaca novas dificuldades sociais trazidas por transformaçóes políticas e econômicas, sem que as antigas tivessem sido superadas. O autor integra múltiplas esferas no caminho para o desenvolvimento, incluindo preocupaçóes com pobreza, desigualdade de renda, ou danos ambientais causados pela industrializaçáo do período anterior.

As "capacitações" são o elemento-chave trazido na conceituação do autor. Em síntese, representam o conjunto de oportunidades ou liberdades que uma pessoa tem para ser o que almeja ou para estar no estado que deseja. Seriam também as capacitaçóes a própria métrica do nível de desenvolvimento de uma comunidade ou nação. Com essa definição de desenvolvimento, o objetivo último de uma sociedade é proporcionar meios para que cada pessoa atinja as liberdades que valoriza (Sen, 2010).

Desenvolvimento é, portanto, um processo de expansão das liberdades das quais os indivíduos podem dispor. Ao mesmo tempo, Sen (2010) ressalta que problemas como a fome são capazes de privar os indivíduos da faculdade

6. Utilizamos a Survey of Adult Skills, pesquisa que entrevistou pessoas de 16 a 65 anos em diversos países da OCDE, com o foco de mostrar como adultos utilizam o conhecimento obtido e quais benefícios são obtidos por utilizá-los.

7. Como exemplos, citamos a Comissão Econômica para a América Latina e o Caribe (CEPAL), que centrou suas teses e propostas na nova concepção de transformação produtiva com equidade nos anos 1990, ao passo que a OCDE criou, em 1994, o serviço de desenvolvimento territorial. Por fim, a incorporação do aspecto ambiental no desenvolvimento pode ser ilustrada pela elaboração da Agenda 21 durante a Conferência das Nações Unidas sobre Meio Ambiente e Desenvolvimento, em 1992. 
de fazer escolhas. Desta maneira, para se buscar o desenvolvimento, deve-se, também, eliminar privaçóes, fazendo com que o indivíduo possa desfrutar de liberdades efetivas.

O crescimento econômico pode contribuir muito para a expansão de liberdades e para a eliminação de privaçôes, mas não é sinônimo de desenvolvimento. Crescimento econômico é sim uma forma de expandir possibilidades e facilitar o alcance de objetivos maiores, como a melhora na qualidade de vida das pessoas e sua liberdade de escolha (Sen, 1983). No entanto, ainda que um país seja rico, náo se pode afirmar que ele seja desenvolvido. Um alto grau de desigualdade na distribuição de sua riqueza, por exemplo, pode impedir uma sociedade rica de prover oportunidades a seus indivíduos.

Ao defrontar-se com uma cobrança para tornar mais objetivas as recomendaçôes de políticas, Sen (2010) sugere um conjunto de liberdades cujos papeis constitutivo e instrumental se destacam, e seriam prioritárias no processo de escolha social e na formulação de políticas públicas: liberdades políticas, meios econômicos, oportunidades sociais, garantias de transparência e rede de seguridade protetora. ${ }^{8}$

Por oportunidades sociais, Sen (2010) refere-se basicamente à oferta de serviços como saúde e educação, cujos benefícios proporcionam uma vida melhor para os indivíduos. Cuidados com saúde são capazes de melhorar a qualidade de vida em todas as etapas do desenvolvimento de um indivíduo, além de alongar sua expectativa de vida.

Por sua vez, a educação pode ser entendida por meio de três óticas: a primeira, como uma forma de liberdade que o indivíduo deseja e à qual dá valor; ele enxerga benefícios em saber ler, saber se comunicar e argumentar melhor ou, ainda, em ser visto com mais seriedade pelos demais. Quando compreende-se a educação por essa relação direta com as liberdades das pessoas, ela é um fim em si mesma, e assume sua forma "constitutiva" do desenvolvimento, aspecto inovador e contrastante com teorias de desenvolvimento anteriores. A literatura até entâo, especialmente a teoria do capital humano, ${ }^{9}$ valorizava excessivamente uma segunda ótica, qual seja, o papel que a educação desempenha como meio para aumento de produtividade, contribuindo indiretamente para o processo de desenvolvimento. Nessa perspectiva, o capital humano compóe o processo produtivo tal qual o capital físico (Sen, 1998).

Sen (2010) reconhece a importância dessa função, mas, ao mesmo tempo, também enxerga que, ao se educar, o indivíduo está eliminando um tipo de privação que o impede de desfrutar de uma vida plena; ela contribui para a promoção de

8. Tradução livre para: political freedoms, economic facilities, social opportunities, transparency guarantees e protective security.

9. Ver Becker (1964) e Schultz (1960). 
outros tipos de liberdade. Portanto, sob uma terceira ótica, o autor compreende que a educação também desempenha um outro papel instrumental, na medida em que aumenta o potencial do indivíduo de realizar outros desejos, proporcionando, por exemplo, meios para se viver melhor - de fato, o nível educacional é um dos determinantes da posição de uma pessoa no mercado de trabalho, inclusive da renda ao longo da vida.

$\mathrm{Na}$ mesma linha, podem ser apontados outros exemplos de contribuição da educação aos indivíduos, que se assemelham à visão de Sen, como facilitar sua participação em debates públicos, reduzir morbidade e mortalidade, entre tantas outras. ${ }^{10}$ Feinstein et al. (2008) compilaram algumas pesquisas sobre benefícios pessoais e sociais do aprendizado, que revelaram a existência de evidências, diretas ou indiretas, de que indivíduos mais educados desenvolvem: i) maior predisposição ao autocontrole e ao cuidado com a saúde; ii) um comportamento mais adequado em sociedade, englobando interação interpessoal, reafirmação de valores como respeito, tolerância e compreensão a visões e opiniôes divergentes; e iii) o fortalecimento da cidadania, através do engajamento em trabalho voluntário e atividades políticas.

Em contraste, os autores destacam também as situaçóes em que a educação pode produzir efeitos potencialmente negativos aos indivíduos e à sociedade. É o caso de quando o conteúdo é difícil demais para o estudante, quando são criadas expectativas inatingíveis, ou, ainda, quando o aprendizado beneficia uma pessoa em detrimento de outra, o que pode ocorrer em contextos de desigualdade, pois indivíduos mais educados têm acesso a mais oportunidades que os demais (Feinstein et al., 2008).

Eccles et al. (1993) ressaltaram que fatores que compóem o ambiente escolar tais como a relação entre alunos e professores, as práticas de controle e disciplina utilizadas pelos professores, as oportunidades de os alunos tomarem decisôes - estão relacionadas à motivação dos estudantes, especialmente durante a chamada middle school (ensino intermediário, estágio anterior ao ensino secundário ou médio). Para os autores, declínios na motivação e na autoestima dos alunos podem levar a um baixo desempenho acadêmico e, até mesmo, à vontade de abandonar a escola.

Por diversos meios, a educação pode impactar as liberdades de cada pessoaseu conjunto de "capacitaçóes" - expandindo-as ou restringindo-as. Nas seçóes que seguem, procura-se analisar o papel da educação no desenvolvimento de Coreia do Sul e Finlândia, a fim de compreender em que medida fomentaram o desenvolvimento tal como concebido por Sen.

10. Sosa et al. (2012) analisaram as taxas de óbito de idosos em países da América Latina, na China e na Índia e concluíram que o nível de educação formal recebido pelas pessoas no começo da vida impacta nas taxas de mortalidade, por serem elemento influenciador no tipo de vida que as pessoas levarão: condições de emprego e de saúde. 


\section{PAPEL DA EDUCAÇÃO NA ESTRATÉGIA DE DESENVOLVIMENTO SUL-COREANA}

Desde antes da Proclamação da República da Coreia do Sul, em 1948, a noção de promoção da educação já permeava a cultura do país. Governos anteriores haviam disseminado a ideia de democratizaçáo da educação, entre outras razóes, para que o país pudesse se reerguer no pós-guerra. A Constituição sul-coreana também previa a implementação de educação compulsória como promotora de oportunidades (Yoon, 2014). Nessa época, sob um regime de governo autoritário, a política educacional dava grande relevância ao desenvolvimento pessoal, visando promover características do cidadão ideal na visão do governo: preocupado com a defesa nacional e anticomunista.

A partir de 1953, finda a Guerra da Coreia, que deixou o país e a população em condiçóes extremamente desfavoráveis, um grande volume de recursos externos, principalmente norte-americanos, foi recebido com a função de reconstruir o país. Como estratégia para o desenvolvimento do setor industrial, o governo sul-coreano envidou fortes esforços em práticas de defesa econômica contra a concorrência externa.

Segundo Lim (2003), esse protecionismo acarretou em uma economia extremamente dependente de assistência externa na década de 1960, tendo a Coreia do Sul uma das mais baixas rendas per capita do mundo. Seth (2010) ressalta a visão pessimista mundial nesse momento acerca do país e a dúvida sobre sua recuperação. As projeções indicavam que a dependência do auxílio dos Estados Unidos se arrastaria por mais décadas.

No entanto, duas mudanças fundamentais ocorreram na sociedade sul-coreana durante os anos 1950 e são consideradas como os pilares facilitadores da grande arrancada econômica que estava por vir na década seguinte: a reforma agrária defendida pelos Estados Unidos - e a expansão da educação. Com $70 \%$ a 80\% do volume de gastos públicos com educação destinados à educação primária, a taxa de alfabetização cresceu de 22\% em 1945 para aproximadamente 80\% em 1960 (Lee, 1997). Foi alcançada a universalização do acesso nesse estágio, elemento fundamental para que se pudesse pensar na industrialização dos anos seguintes (World Bank, 2006).

A partir dos anos 1960, foram lançados seis sucessivos Planos Quinquenais de Desenvolvimento Econômico, instrumentos de planejamento do Estado, com objetivos de longo prazo, que eram adaptados de acordo com a situação corrente. A consolidação das metas inscritas em cada um dos planos promoveu dinamismo na indústria sul-coreana, com investimentos em setores cada vez mais sofisticados, com expressivos resultados em termos de crescimento econômico, e que somente se fizeram possíveis dado o grau de instrução da população, impulsionado pelos investimentos prévios em educação (Seth, 2010). 
Durante as fases iniciais, quando o foco era a industrialização do país, com a efetivação de uma estrutura econômica voltada para as exportaçóes, o governo sul-coreano buscou alinhar as políticas educacionais à estratégia de qualificar a mão de obra para atender às necessidades da indústria. Yoon (2014) afirma que, diante dessa demanda, o governo procurava formar recursos humanos dotados da habilidade e da produtividade necessárias para a industrialização. De início, a ênfase recaiu sobre a educação técnica. Aos poucos, ao final da década de 1960, o foco tornou-se o ensino secundário (Kim, 2002).

Nessa época, a expansão da formação secundária foi importante e, por meio de políticas específicas - que nem sempre possuíam, deliberadamente, esse objetivo -, alcançou-se a cobertura universal desse nível. Em 1968, foi extinto o exame de seleçáo ao qual eram submetidos os estudantes que completavam o ensino primário e direcionavam-se ao estágio seguinte (nível intermediário) ${ }^{11} \mathrm{e}$, em 1974, medida similar foi adotada com relação ao exame de seleção para entrada no nível secundário (ou médio). Ambos foram substituídos por um sistema em que vagas em escolas públicas e privadas eram sorteadas aos estudantes que completassem o nível de ensino anterior (Kim, 2002). Como resultado, houve expressivo aumento de estudantes ingressantes no ensino secundário: o número de matriculados quadriplicou entre 1961 e 1980 (Seth, 2010). Esse crescimento acelerado resultou em escolas e salas de aula superlotadas, porque não foi acompanhado do incremento na oferta de professores. Consequentemente, houve queda na qualidade do ensino sul-coreano e um acirramento na competição das escolas de ensino médio (Kim, 2002).

Numa tentativa de padronizar o ensino nas escolas de nível secundário, foi instituído, em 1968, o primeiro exame para ingresso no ensino superior. Ocorre que, uma vez que a educação formal era considerada insuficiente para aprovação nesse exame de seleção, os pais sul-coreanos buscavam compensar o ritmo de aprendizagem com a contratação de aulas extras (Seth, 2010), tema importante ao qual retornaremos mais adiante.

Na década de 1970, com o lançamento do III Plano Quinquenal de Desenvolvimento Econômico, cuja ênfase repousava sobre indústria pesada e química, a conexão entre o plano de desenvolvimento e as políticas educacionais tornou-se ainda mais evidente. Nessa década, o governo dobrou os gastos destinados à educação vocacional, haja vista sua demanda por mão de obra técnica. Também foram criadas as primeiras universidades e escolas de ensino secundário à distância, além de uma estrutura de escolas especiais para alunos que trabalhavam (Yoon, 2014).

11. Este ensino intermediário inicia-se após quatro anos de ensino elementar, geralmente quando a criança atinge os dez anos de idade. 
Por sua vez, nos anos 1980, quando floresceu o desejo de guinar a indústria sul-coreana para uma economia intensiva em tecnologia apoiada em indústrias de alto valor agregado, surge o desafio de penetrar o mercado dominado pelos países desenvolvidos. $\mathrm{O}$ foco passou para o desenvolvimento do ensino superior e investimentos em pesquisa e desenvolvimento ( $P \& D)$.

Buscando atender à demanda popular por um aumento de vagas em universidades, o governo efetivou, em 1980, uma grande reforma que expandiu largamente as vagas para entrada de estudantes em instituiçóes de ensino superior. $\mathrm{O}$ total de matrículas em instituiçóes de ensino superior passou de cerca de 600 mil, em 1980, para aproximadamente 1,5 milhão, em 1990 (Seth, 2002). Para contrabalançar o aumento no número de matrículas, foi instituído um draconiano sistema de controle de qualidade, segundo o qual cada universidade deveria cancelar a matrícula dos estudantes que ficassem entre os $30 \%$ de mais baixo rendimento (Lee, 2000). Em síntese, afrouxou-se o controle do número de estudantes que ingressavam na universidade para estreitar-se o controle daqueles que se graduariam. O impopular sistema sofreu forte resistência dos estudantes e, em 1984, foi abolido.

Foi durante esses quase trinta anos de ditadura (de 1948 a 1979) - e mais quase uma década (de 1980 a 1987) que ainda sentiu os reflexos de um regime autoritário - que se deu a transformação econômica da Coreia do Sul, por vezes chamada de "milagre econômico" (Seth, 2010). A virada de chave se deu nos anos 1990 e afetou, também, os objetivos preconizados pelas políticas educacionais.

Em meio à onda redemocratizante da Coreia do Sul, e dada a universalização já alcançada nos níveis de ensino primário e secundário, a educação superior encontrava um novo desafio: o desequilíbrio entre a expansão nas matrículas e a queda de qualidade no ensino não era compatível com a sociedade avançada que se projetava para o país. Com o intuito de elevar o país ao patamar dos países avançados e diante do novo cenário marcado pela globalização, uma reforma foi lançada em 1995 a partir do relatório da Comissão Presidencial de Reforma Educacional, constituída no ano anterior. O novo sistema estava calcado em dois pilares: diversificar e especializar as universidades de modo a promover maior qualidade de ensino; e a necessidade de criar um novo método de ingresso na universidade que aliviasse o fardo das famílias com educação suplementar (Lee, 2000).

Segundo Yoon (2014), o governo Kim buscou, neste novo cenário, criar comunidades escolares locais autônomas, em contraste com o controle administrativo central aplicado pelos governos anteriores. Adicionalmente, buscou-se disseminar uma nova filosofia educacional que incentivasse a criatividade e desenvolvesse a personalidade dos alunos através da revisão do currículo escolar. Dentro dos 48 objetivos da reforma, também foi prevista a remodelagem da política em favor do bem-estar dos professores, programas educacionais diversificados, além 
da destinação de $5 \%$ do produto interno bruto (PIB) para os gastos do governo em educação (OECD, 2014). Vale ressaltar que, de acordo com os registros de Kong et al. (1994, apud Lee, 1995), o percentual desses gastos girava em torno de $3,6 \%$ nos cinco anos anteriores.

Durante os anos 1990, a economia sul-coreana começou a orientar-se cada vez mais para a tecnologia e a inovaçáo. $\mathrm{Na}$ busca pela redução da dependência externa, foi reconhecido nacionalmente que o sucesso dessa estratégia dependia diretamente do desenvolvimento de conhecimento dos cidadáos sul-coreanos, ainda que com a adoção de tecnologias estrangeiras. Isso justifica a elevação dos gastos com P\&D que, em 2004, alcançaram 2,84\% do PIB sul-coreano (World Bank, 2006). Essa elevação foi fruto, principalmente, de investimentos do setor privado - que responde, em média, por $75 \%$ do total investido em P\&D nas últimas décadas - puxados pelo rápido crescimento econômico. Esse intenso investimento em P\&D refletiu-se em crescimento no número de patentes geradas, na produção acadêmica do país e no volume de royalties e pagamentos de licenças recebidos pela Coreia do Sul (OECD, 2014).

\section{ASPECTOS SINGULARES DA EDUCAÇÃO SUL-COREANA}

É inegável que o governo sul-coreano tem envidado esforços para progredir em termos de resultados educacionais, fornecendo insumos para fomentar a competitividade de sua economia frente aos desafios globais. As diversas reformas postas em prática ao longo dos anos desembocaram no sistema educacional atual, considerado de excelência em termos de desempenho em exames padronizados como o Pisa, e que possui características dignas de serem apreciadas. Uma delas refere-se ao fato de, tradicionalmente, as autoridades sul-coreanas se utilizarem de avaliaçóes como insumo para traçar planos visando aprimorar a qualidade do ensino. Alunos, professores e escolas são periodicamente avaliados, com o objetivo de se conhecer o que de fato ocorre nas escolas, e para que possam ser traçadas políticas adequadas às reais carências.

\subsection{A importância da aprovação e o ipsijiok (o inferno do vestibular) ${ }^{12}$}

$\mathrm{O}$ ingresso em uma universidade sul-coreana de excelência reconhecida é bastante difícil para o aluno. O Suneung é o exame de ingresso mais importante, uma espécie de vestibular, cuja pontuação irá determinar em qual universidade o aluno irá cursar seu ensino superior. Há quem diga que a educação sul-coreana gira em torno desse exame, que se dá uma vez ao ano e é um evento nacional.

12. A expressão em coreano é 涝矫瘤吉, ou ipsijiok. Ipsi significa todo o processo de ingresso na universidade (preparação, exames, candidatura etc.), enquanto jiok significa inferno ou infernal. 
Apesar de ser aplicado aos alunos em fase de conclusão do ensino secundário, o exame movimenta todo o país. Pousos e decolagens ficam restritos para garantir que o ruído dos avióes não atrapalhe as provas, assim como é recomendado aos motoristas que não buzinem próximo a escolas durante a aplicação das provas. Com relação ao trânsito, visando evitar percalços como engarrafamento ou acidentes no deslocamento dos alunos aos locais de prova, a jornada de trabalho da população é adiada. Toda essa precaução reflete a importância atribuída ao exame e o espírito de cooperação nacional para o sucesso dos candidatos.

É um momento decisivo na vida do jovem sul-coreano, pois uma boa pontuação é o que irá lhe possibilitar estudar nas melhores universidades e aspirar a um futuro próspero para ele e para sua família. Segundo Lee (2003), a pressão para se sair bem nesse exame é o que estrutura a vida de um adolescente sul-coreano, que dedica a maior parte do tempo aos estudos e conta com pouco tempo livre para lazer. A situação aqui descrita por vezes é chamada de ipsijiok (o inferno do vestibular) (Lee, 2003).

Lee (2003) também ressalta que o ritmo de aulas nas escolas de ensino médio é ditado pela capacidade de aprendizado dos melhores alunos da turma, isto é, aqueles que têm condiçóes de serem aprovados no exame universitário. Os demais acabam passando o mesmo tempo na escola que os alunos mais preparados, entretanto enfrentam maior dificuldade para assimilar o conteúdo. Essa situação é preocupante, pois pode ensejar exclusão ou marginalização daqueles de mais baixo desempenho, o que, de acordo com a abordagem das capacitaçóes, vai de encontro ao que se considera a função benéfica da educação para o futuro do indivíduo (Walker e Unterhalter, 2007).

\subsection{0 consumo informal de educação suplementar}

Dado que nem todas as escolas preparam os alunos suficientemente para os rigorosos exames de ingresso nas universidades, sobre as famílias recai o fardo de complementar a preparação dos estudantes. No contexto cultural sul-coreano, pais e responsáveis estão dispostos a investir tantos recursos quanto possível na educação das crianças, de modo a proporcionar-lhes as melhores oportunidades, sobretudo o ingresso em boas universidades, porta de entrada para uma boa colocação no mercado de trabalho. Famílias com recursos buscam meios alternativos para enriquecer o grau de instrução dos estudantes nos níveis de ensino básico e secundário. E é a partir desta lacuna que surge o fenômeno conhecido como "aulas suplementares".

Bastante difundida nos países do Leste Asiático, a educação suplementar à formal é composta tanto do que conhecemos como aulas particulares (ou tutoria) como de instituiçóes privadas informais, denominadas por OECD (2014) de shadow education. Estima-se que, em 2012, 81\% dos estudantes de nível primário recebiam 
aulas suplementares, enquanto no secundário a participação gravitava entre 50\% e $70 \%$ (OECD, 2014). Números esses que corroboram a visão explicitada por Yoon (2014), de que existe uma descrença da população sul-coreana com relação ao ensino público formal.

Aliado a outros fatores culturais e pedagógicos, o surgimento do fenômeno está intimamente ligado à existência de exames de ingresso em instituiçôes de ensino. Assim como no Brasil, também na Coreia do Sul as provas equivalentes ao vestibular provocaram a disseminação de cursos preparatórios, sobretudo à medida que a renda da população foi se elevando como consequência do longo período de crescimento do país (OECD, 2014).

Muitas são as desvantagens da existência de tal fenômeno em um sistema educacional. Bray e Lykins (2012) detalham esses impactos. De maneira geral, em termos de bem-estar, alunos passam a estudar mais horas por dia e, portanto, deixam de ter tempo livre para lazer. Em termos pedagógicos, estudantes aprendem antecipadamente tópicos que ainda serão abordados nas aulas formais, o que cria dificuldades para os professores aplicarem seus métodos de ensino e aumenta as discrepâncias entre estudantes numa mesma sala de aula.

Por fim, em termos econômicos, a educação suplementar pode provocar desequilíbrios e ineficiência no sistema educacional como um todo. É muito comum que os alunos prefiram tirar suas dúvidas com os tutores particulares do que com os professores das escolas. Os alunos tendem a prestar mais atenção a quem seus pais estáo pagando diretamente do que aos professores na escola, o que subvaloriza cada vez mais o sistema escolar. Mais ainda, a longa jornada de estudos dos alunos faz com que os mesmos estejam com menos energia durante as aulas escolares, não sendo incomum encontrar alunos dormindo durante a aula, tornando-a ainda mais ineficiente.

OECD (2014) acredita que esse comportamento, que dá ênfase em um maior número de horas de estudo dentro e fora das escolas, reflete a interpretação da educação meramente como um meio de adquirir conhecimento tradicional. Essa visão repercute, ainda que de forma limitada, o papel instrumental da educação, contudo despreza por inteiro sua própria forma constitutiva de desenvolvimento pessoal e social.

\section{PAPEL DA EDUCAÇÃO NA ESTRATÉGIA DE DESENVOLVIMENTO FINLANDESA}

$\mathrm{Na}$ década de 1990, a Finlândia superou uma crise macroeconômica por meio de uma estratégia de desenvolvimento que foi essencialmente fortalecida por seus princípios do welfare state. A economia encontrava-se enfraquecida em razão da obsolescência do modelo econômico praticado até então, baseado em recursos naturais. Recuperou-se da crise e consolidou-se em patamares elevados de crescimento e de desenvolvimento com o estímulo a indústrias do mais alto padrão de sofisticação em termos de conhecimento e tecnologia. 
Arbix e Ferraz (2009), ao sumarizar esse movimento de transformação da economia finlandesa, concluem que o alto padrão produtivo somente se fez possível pela atenção dada às políticas sociais nas décadas anteriores, sobretudo o maciço investimento em educaçáo observado a partir do final da década de 1960, ainda que tais políticas não tivessem deliberadamente como objetivo último alcançar o alto padrão de sofisticação mencionado. Foram promovidas reformas graduais, tendo como propósito muito mais uma universalização e uma redução da desigualdade do que a formação de mão de obra altamente qualificada. Tais reformas estenderam a cobertura do ensino por todo o país e culminaram na criação do sistema educacional que hoje é considerado um dos melhores do mundo.

Até fins do século XIX, a economia finlandesa ancorou-se apenas em seus recursos naturais (Arbix e Ferraz, 2009), apresentando uma estrutura produtiva muito pouco complexa - no sentido de complexidade adotado por Gala, Rocha e Magacho (2016). ${ }^{13}$ Enquanto os países líderes da Europa avançavam com os benefícios da industrialização, a Finlândia não possuía recursos para tal, muito em função de suas características geográficas. Com $76 \%$ de seu território coberto por florestas, de acordo com Parviainen (2010), madeira era a matéria-prima finlandesa mais barata e abundante. Suas condiçôes climáticas eram desfavoráveis à agricultura. A combinação de recursos energéticos escassos e elevado consumo de energia, tanto doméstica (longos e rigorosos invernos demandam aquecedores nas residências) quanto industrial (majoritariamente na produçáo de papel e celulose), contribuiu para a necessidade de se importar alimentos e matérias-primas.

Diante do alto volume de importaçóes e da abundância de produtos derivados de madeira direcionados ao mercado internacional, o comércio externo finlandês sempre foi bastante intenso, ocupando papel central na economia nacional. Tanto exportaçôes quanto importaçôes oscilavam entre $20 \%$ e $30 \%$ do PIB finlandês, entre 1970 e 1992, e a partir de 1993 elevaram-se as exportações a níveis próximos a 40\%, enquanto as importaçóes alcançaram cerca de um terço do PIB. ${ }^{14}$

De acordo com Arbix e Ferraz (2009), foi a renda proveniente das exportaçôes que permitiu a acumulação de capital necessária para o desenvolvimento das indústrias baseadas em recursos florestais. Em 1980, as indústrias de madeira e produtos derivados, papel e celulose respondiam por $45 \%$ da pauta de exportações do país, ${ }^{15}$ um pouco inferior ao registrado em anos anteriores. Por sua vez, em 2006, essas indústrias passaram a representar somente $21 \%$ das exportações,

13. Gala, Rocha e Magacho (2016) trabalham o conceito de complexidade produtiva, trazido do Atlas da Complexidade Econômica, desenvolvido por Hidalgo e Hausmann (2009). Ela é medida diretamente pelo grau de diversificação dos produtos que compõem a pauta de exportações de um país e pelo grau de não ubiquidade dos mesmos (bens não ubíquos são bens raros, de difícil produção - como os intensivos em tecnologia - ou aqueles extremamente difíceis de encontrar na natureza). Diz-se que há complexidade produtiva quando ambas características estão presentes.

14. Informações retiradas de World Bank ([s.d.]).

15. Informações retiradas de Finnish Board of Customs e Confederation of Finnish Industries (apud Arbix e Ferraz, 2009). 
cedendo espaço a produtos eletrônicos e eletroeletrônicos, os quais, no mesmo período, saltam de $4 \%$ para um quarto do volume total exportado. Experiência notável pela rapidez com que ocorreu: em pouco mais de vinte anos, a Finlândia modificou consideravelmente o padrão de sua estrutura produtiva.

Essa mudança foi resultado de uma combinação das decisões de longo prazo (manutenção nos investimentos em inovação, educação, ciência e tecnologia) e das decisôes tomadas para recuperação da crise econômica vivenciada pela Finlândia no início da década de 1990 (Arbix e Ferraz, 2009). Tendo aderido à onda de liberalização e desregulamentação financeira durante a década anterior, e contando com uma condição internacional favorável aos termos de troca - por meio da valorização nos preços dos produtos florestais -, o país sofreu um superaquecimento da economia ${ }^{16}$ (Haffner e Oliveira, 2014). ${ }^{17}$

Com a demanda agregada estimulada, o quadro era de deficit na balança de pagamentos, desequilíbrio nas contas públicas, elevado nível de dívida do setor privado, bem como de inflação no mercado imobiliário. Além disso, como pontuado por Arbix e Ferraz (2009), viu-se um declínio nas receitas causado pelo desmantelamento da União Soviética, que, à época, constituía um dos principais destinos das exportações finlandesas. Essa combinação provocou retração no crescimento do PIB finlandês entre 1991 e 1993 . Além da perda de poder de compra da população acarretada pela alta inflação, o desemprego, que havia sido reduzido a cerca de 2,5\% durante o período de superaquecimento, pulou para mais de $15 \%$ em 1993, mantendo-se neste patamar por mais dois anos.

A superação da crise deu-se por um esforço político e macroeconômico para reequilíbrio das contas públicas. O governo finlandês adotou medidas macroeconômicas como câmbio flutuante em 1992 e um ajuste fiscal entre 1991 e 1994 . As opções internas de política coincidiram com a oportunidade de integração do país à União Europeia - a exemplo da Coreia do Sul, portanto, elemento exógeno não-recorrente também parece ter contribuído no processo de catching up finlandês. Como resultado, as exportaçôes voltaram a crescer e a demanda agregada foi contraída a níveis suportáveis.

A despeito dos avanços que já haviam ocorrido com a introdução de tecnologias mais evoluídas nas indústrias existentes, a crise revelou como era frágil uma economia baseada na exportação de produtos de madeira, papel e celulose num contexto de avanço tecnológico global (Arbix e Ferraz, 2009). Foi nesse momento

16. Provocado pelo aumento na concessão de crédito e no fluxo de entrada e saída de capitais (estimulado pelos empréstimos externos ilimitados).

17. 0 modo como se deu essa crise e sua superação foi sumarizado no artigo de Haffner e Oliveira (2014), que serviu como fonte para este parágrafo e para os dois parágrafos seguintes, além das fontes complementares que foram indicadas no próprio texto. 
de recuperação econômica que a necessidade de diversificação das exportaçóes e das indústrias finlandesas veio à tona. Diante dos novos desafios que a economia finlandesa enfrentava, ficou clara a percepção de que uma nova estratégia de desenvolvimento nacional deveria ser adotada (Haffner e Oliveira, 2014).

Buscou-se orientar a prioridade dos investimentos para as indústrias de tecnologia da informação e de comunicação, aliada também a um grande incentivo à inovação tecnológica, sob a justificativa de que tal agenda política possibilitaria a implementação de pacotes de mudança estrutural, dispensando a necessidade de mais liberalização ou desregulamentação, além de gerar emprego e spillovers na indústria existente (Ornston e Rehn, 2006).

A produção de bens complexos requer aptidóes sofisticadas e uma organização tal que seja possível processar esse conhecimento (Hidalgo e Hausmann, 2009). Numa economia baseada em tecnologia de informação, comunicação e inovação, é fundamental que a mão de obra possua características como habilidade de formulação e processamento de dados, bem como capacidade de produção e administração de informações (Dahlman, Routti e Ylä-Anttila, 2006).

Essa demanda foi suprida na medida em que a sociedade tinha níveis de instrução elevados: cerca de $35 \%$ da população acima de 25 anos tinha ao menos secundário completo, enquanto $23 \%$ da população tinha diploma de ensino superior. ${ }^{18}$ Mais tarde, a Finlândia passou a ocupar as primeiras posiçōes nos rankings como o Pisa, cuja primeira rodada ocorreu em 2000, revelando que o sistema finlandês era também muito bem-sucedido em preparar seus alunos para resolver problemas.

A implementação da nova estratégia calcada em indústria de tecnologias avançadas somente se fez possível haja vista o maciço investimento na educação da população desde a década de 1970. A primeira grande reforma, iniciada em 1968, havia fixado como objetivo reverter o quadro de segregaçáo social propiciado pelo sistema educacional que vigorava até então. Havia dois tipos de ensino intermediário, que em grande medida determinavam o futuro acadêmico e profissional dos jovens, por não ser permitida mobilidade entre essas duas modalidades de ensino: o oppikoulu (em finlandês), cujo ensino era voltado para a carreira acadêmica e cujo acesso era limitado aos mais afortunados, e o kansalaiskoulu, que poderia levar a uma carreira mais técnica. Foi, então, criado um sistema de educação básica completamente novo (peruskoulu), ${ }^{19}$ que unificou as duas modalidades de ensino. Tal reforma é considerada bastante ambiciosa, na medida em que colocou estudantes de diferentes condiçóes socioeconômicas e habilidades estudando lado a lado na mesma sala de aula, gerenciada e financiada pelo setor público (OECD, 2014).

18. Informações retiradas de Tilastokeskus ([s.d.]).

19. Os termos em inglês mais difundidos na literatura internacional são, respectivamente: grammar schools, civic schools e comprehensive schools. 
É natural que, diante de uma reforma tão ousada, surgissem desafios. Para superá-los, fez-se necessário um corpo docente qualificado e preparado para atuar no novo ambiente de ensino, com métodos modernos e instrumentos de aprendizado eficazes para diferentes tipos de alunos. Ao final dos anos 1970, foi promovida na Finlândia uma reforma na carreira do magistério, ${ }^{20}$ por meio da qual todos os programas de formação de professores passaram a ser de nível universitário e o requisito mínimo para lecionar na escola básica e secundária passou a ser o grau de mestrado. A profissão passou a ser mais valorizada e, atualmente, atrai milhares de jovens, tornando o processo bastante competitivo (OECD, 2014).

Quando da crise econômica dos anos 1990 e do consequente aumento de demanda por mão de obra qualificada para viabilizar a estratégia de recuperação da economia pela transformação da estrutura produtiva, o ensino superior precisou ser intensificado, de modo a formar uma oferta de trabalhadores com o perfil necessário para a nova indústria especializada em tecnologia. No início da década de 1990, cerca de $23 \%$ da população de 25 a 64 anos possuía diploma de ensino superior, ao passo que, ao final dessa década, esta participaçáo havia aumentado para mais de $31 \%$.

Ainda que tenha suscitado dúvidas quanto a sua eficácia nos anos recentes, a educação finlandesa é internacionalmente reconhecida não só por seus resultados em exames padronizados como o Pisa, mas também por ser peculiar na forma de ensino. Esse modelo não persegue táo-somente os bons resultados de seus alunos em exames internacionais, mas também preocupa-se com o desenvolvimento de competências relevantes nos indivíduos, como talento, criatividade e perspicácia (OECD, 2014). Num contexto de welfare state característico da região, no qual é responsabilidade do Estado o provimento de serviços de qualidade para toda a população, isso é feito de forma majoritariamente gratuita para a população e a custos não tấo elevados para o Estado.

\section{ASPECTOS SINGULARES DA EDUCAÇÃO FINLANDESA}

Nas últimas décadas, o sucesso educacional finlandês despertou a curiosidade de todo o mundo. Professores, diretores, pedagogos e formuladores de política passaram a visitar as escolas da Finlândia buscando entender a filosofia por trás do sistema que é capaz de produzir um desempenho elevado dos alunos em exames como o Pisa, sem que as escolas valorizem excessivamente o ensino das matérias objeto do exame.

De acordo com OECD (2015), a Finlândia está entre os países que possuem mais baixa variação entre as escolas em termos de performance no Pisa. Com isso, o sistema educacional finlandês aparenta desempenhar muito bem uma função 
equalizadora de oportunidades, isto é, tendo em vista que os alunos finlandeses, de um modo geral, recebem uma educação pouco dispersa em nível de qualidade, as chances de sucesso no futuro são bem distribuídas. Além disso, a valorização da carreira docente também chama atenção. Com salários compatíveis com os das mais concorridas carreiras, prestígio, treinamentos de alto padrão e autonomia para lecionar, o professor finlandês encontra um ciclo de sucesso na profissão.

\subsection{Estrutura curricular com ênfase em quê?}

Buscando explicar como se deu a transformação, em termos de qualidade, do sistema educacional finlandês, Sahlberg (2007) pontua a dificuldade de identificar aspectos específicos que levaram ao sucesso atual. $\mathrm{O}$ autor ressalta que, mais importante que esta análise limitada, é observar as transformaçóes mais amplas em termos de objetivos e diretrizes gerais que introduziram e reforçaram os princípios norteadores da evolução do sistema educacional.

Nesse sentido, Sahlberg (2007) destaca que a Finlândia seguiu em direção oposta às tendências de políticas e reformas educacionais que emergiram mundialmente nos anos 1980. Os ideais internacionalmente difundidos na época estavam focados em: i) ensino padronizado e orientado a resultados; ii) foco em desenvolver habilidades de leitura, matemática e ciências naturais, em detrimento de artes ou ciências sociais; e iii) o consequente modo de avaliação de escolas e professores com aplicação de testes externos e estabelecimento de metas de performance limitadas aos objetivos anteriormente descritos.

Em contraste, o sistema educacional finlandês é produto de melhorias construídas sobre a noção de flexibilidade e confiança: currículos adaptáveis, inovadores, ajustados para realidades específicas e focados no aprendizado mais amplo. No decorrer do processo de aprendizagem, alunos e professores são encorajados a adotar açóes criativas e inovadoras. Este tipo de educação atribui o mesmo valor que é dado às habilidades técnicas aos demais aspectos do desenvolvimento humano, tais como: personalidade, criatividade, ética, moralidade e talentos (OECD, 2014).

Os princípios que norteiam a educação finlandesa têm como objetivo não somente a formação de profissionais competentes, com vistas a assegurar o crescimento da economia, mas também o desenvolvimento de indivíduos capazes de lidar com os desafios modernos de maneira eficaz, criativa e inovadora (OECD, 2014).

Vale registrar que algumas universidades finlandesas incluem um exame de ingresso em seus processos seletivos, assim como ocorre em vários outros países. No entanto, a aplicação dessa seleção não é tão impactante na vida dos alunos como o é na Coreia do Sul. Além disso, fazem parte da seleção das universidades aspectos que não apenas os resultados no exame, tais como adequação do aluno aos valores da universidade, experiência de vida e trabalho, motivação, entre outros. 


\subsection{Valorização do docente e autonomia da comunidade escolar}

Desde a grande reforma dos anos 1970, que revolucionou a educação básica com a criação do sistema peruskoulu, cada escola é vista como uma minidemocracia (OECD, 2014). Professores foram treinados e incentivados a se desenvolver profissionalmente para que estivessem preparados para lidar com os novos métodos de ensino que se fizeram necessários dada a diversidade de alunos numa mesma sala de aula. A reforma dos anos 1970 instituiu que a preparaçáo dos professores de todos os níveis passasse a se dar em nível universitário, baseada em conhecimento científico e com metodologias de pesquisa.

Para Sahlberg (2007), o magistério transformou-se numa profissão admirada e valorizada. Para tornar-se professor da educação infantil (dedicada a alunos até os 6 anos de idade), é requerido um diploma de ensino superior e o processo seletivo é bastante competitivo. ${ }^{21}$ No que diz respeito ao ingresso no mercado de professores do ensino básico ou secundário, é necessário ter o diploma de mestrado.

Visto que os profissionais da educação são qualificados para ditar o rumo do ensino, desenvolveu-se uma relação de confiança entre os formuladores de políticas e as escolas. Professores e diretores são reconhecidos como capazes de entender as necessidades do dia a dia, o que proporciona maior liberdade de atuação a esses profissionais (Sahlberg, 2007).

Os princípios gerais da educação são definidos pelo Parlamento finlandês, enquanto cabe ao governo e ao Ministério da Educação concretizá-los. No entanto, como esfera responsável por prover a educação básica, os municípios detêm alto grau de autonomia, tanto na gestão quanto no direcionamento dos recursos. O currículo nacional norteia os objetivos e os princípios a serem seguidos, mas compete à comunidade escolar definir o planejamento e os meios através dos quais cada escola irá atingi-los (OECD, 2014).

Essa liberdade torna o sistema educacional finlandês um exemplo de alternativa ao que se vê em muitos países. Em termos de proficiência, os resultados do Pisa indicam que os currículos finlandeses são bem-sucedidos em transmitir conteúdo e desenvolver a capacidade de resolução de problemas. Além disso, outras características pessoais desejadas são percebidas nos alunos finlandeses, que podem estar ligadas ao método de ensino adotado, conforme veremos a seguir.

21. Os recém-formados do ensino secundário candidatam-se, todos os anos, a oito universidades que possuem o curso de formação de professores. Os candidatos também são submetidos a um exame nacional (ylioppilastutkinto em finlandês, ou matriculation exam, em inglês) composto por provas (escritas e práticas) e entrevistas e, para serem escolhidos, também devem possuir um alto desempenho acadêmico e destacar-se por suas habilidades interpessoais. Anualmente, um em cada dez candidatos é aceito nesse processo (OECD, 2014). 


\section{EFEITOS COLATERAIS DOS DOIS SISTEMAS EDUCACIONAIS: UM COMPARATIVO DE SEUS BENEFÍCIOS E EFEITOS ADVERSOS}

O sistema educacional ao qual os jovens estão submetidos proporciona consequências psicológicas, comportamentais e de outras naturezas. Moos (1974) e Roberts (2006), por exemplo, atribuem ao clima em sala de aula um papel substancial na formação do indivíduo, capaz de impactar no seu processo de aprendizagem e de desenvolvimento social. Passaremos aqui a nos referir a essas consequências como "efeitos colaterais" da experiência escolar.

A edição de 2015 do Pisa investigou pela primeira vez resultados relacionados à qualidade de vida dos alunos, que foram submetidos a um questionário que buscava investigar mais detalhadamente o grau de satisfação dos mesmos com a escola e com a vida, bem como suas aspiraçóes futuras através de suas percepçóes psicológicas, cognitivas, sociais e físicas. Os resultados dessa investigação oferecem um conjunto de informaçóes que engloba tanto indicadores positivos quanto negativos, isto é, são evidenciados os aspectos promotores de bem-estar, ${ }^{22}$ bem como aqueles que o restringem.

Nesta seção, apresentaremos alguns dados que foram extraídos da edição de 2015 do Pisa. Focaremos no resultado das questôes às quais todos os alunos que participaram do Pisa foram submetidos nos questionários preenchidos junto com o exame e que mais se aproximam de uma mensuração do aproveitamento e do contentamento desses alunos com a vida. Colocaremos graficamente os resultados finlandeses e coreanos em comparação (contrapondo os mesmos entre eles e com a média da OCDE) e, assim, buscaremos identificar possíveis efeitos colaterais gerados pelo ambiente escolar resultante dos sistemas dos dois países aqui analisados.

Porém, antes disso, cabe apresentar um dado relevante do resultado do exame de ciências ${ }^{23}$ do Pisa para o estudo aqui proposto. A diferença na pontuação média entre os finlandeses que estudam em escolas menos favorecidas socioeconomicamente e aqueles matriculados em escolas mais favorecidas foi de 47 pontos, ao passo que, na Coreia do Sul, essa diferença foi de mais que o dobro - 110 pontos. Esse aspecto é importante na medida em que a equidade do sistema educacional é, intuitivamente, um componente necessário para que a educação seja capaz de exercer a sua função redistributiva.

Passemos, então, às demais questóes. De início, os alunos foram diretamente questionados sobre sua percepçáo de satisfaçáo com a vida. Numa escala de 0 a 10 , finlandeses atribuíram uma média de 7,9 para seu grau de satisfação com a vida, $44,4 \%$ dos quais disseram estar muito satisfeitos (respostas entre 9 e 10) e somente

22. Bem-estar é utilizado aqui como sinônimo de qualidade de vida, o mesmo sentido utilizado no relatório do Pisa. 23. Matéria à qual foi dada maior ênfase nessa edição do Pisa. 
6,7\% disseram não estar satisfeitos com a vida (respostas entre 0 e 4). Neste quesito, todos os resultados da Finlândia foram superiores à média da OCDE. Por outro lado, na Coreia do Sul a média atribuída pelos alunos ao seu grau de satisfação com a vida foi de 6,4, isto é, 0,9 pontos percentuais (p.p.) abaixo da média da OCDE. Também abaixo da média da OCDE, somente 18,6\% dos alunos sul-coreanos declararam estar muito satisfeitos com a vida, enquanto que mais de um quinto dos sul-coreanos disseram não estar satisfeitos com a vida. Esse comparativo pode ser visualizado no gráfico 1 .

GRÁFICO 1

Percepção dos estudantes quanto à satisfação com a vida (Em \%)

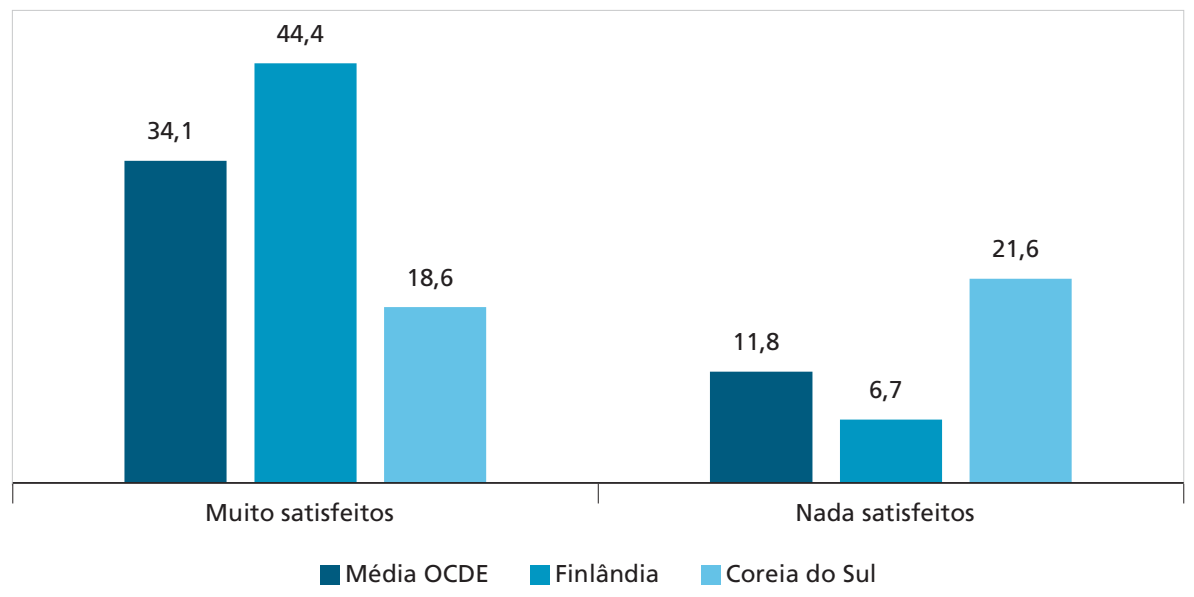

Fonte: OECD (2017).

Elaboração dos autores.

A comparação de níveis de satisfação de indivíduos aproxima-se da tradicional economia do bem-estar, ${ }^{24}$ que tem como mérito colocar a qualidade de vida tal como percebida pelas pessoas no centro da análise. Mas se subjetividade e consequencialismo constituem a força da economia do bem-estar, também são seu calcanhar de aquiles, como apontado com maestria por Sen $(1989 ; 2010)$ em suas obras: i) impossibilidade de se mensurar precisamente o bem-estar; ii) impossibilidade de se comparar o bem-estar interpessoalmente; iii) direitos e liberdades relegados a um segundo plano, visto que só importam por meio de seu eventual impacto sobre o bem-estar; e iv) riscos de adaptação e condicionamento mental. Sen (2010, p. 89) pondera que "é sensato levar em consideração a felicidade, mas não necessariamente desejamos escravos felizes ou vassalos delirantes". Aqueles

24. Referimo-nos à corrente econômica centrada na filosofia utilitarista, na qual o bem-estar individual é mensurado a partir das preferências e do nível de utilidade que os bens geram aos indivíduos, tal como apresentado em Varian (2006). 
que vivem em situaçóes objetivamente degradantes tendem a se conformar com pouco, de modo a tornar a vida mais suportável.

Desta forma, por constituir uma medida subjetiva e maleável, a avaliação e a comparação de satisfação com a vida devem ser feitas com cautela. Por ora, não é conhecido se os sul-coreanos são excessivamente ambiciosos quanto ao nível de satisfação com a vida, ou se outros fatores, que não a educação, influenciaram diretamente em suas respostas, mas o resultado sugere a necessidade de uma maior atenção à satisfação dos jovens sul-coreanos com a vida.

O componente motivacional também foi avaliado por meio da percepção dos alunos. Quando questionados no Pisa sobre a afirmação "Depois de formado, eu quero poder escolher entre as melhores oportunidades disponíveis", $80 \%$ dos finlandeses responderam concordar ou concordar fortemente, ao passo que $96,1 \%$ dos sul-coreanos deram as mesmas respostas. A média da OCDE é de 92,7\%. Os dados constam no gráfico 2.

GRÁFICO 2

Percepção da motivação e da competição entre os estudantes (Em \%)

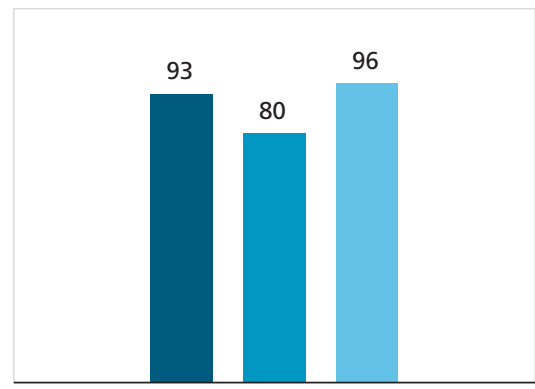

"Depois de formado, eu quero poder escolher entre as melhores oportunidades disponíveis"

Média OCDE Finlândia Coreia do Sul

Elaboração dos autores.

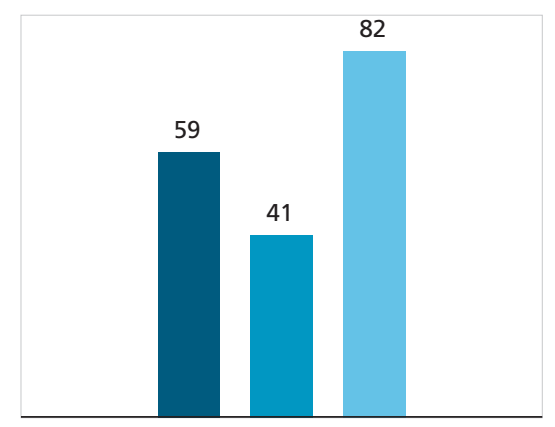

"Eu quero ser um dos melhores alunos da minha turma"

Média OCDE Finlândia Coreia do Sul

Segundo OECD (2017), essa é uma medida de motivação, pois reflete o valor que os alunos dão às atividades que estão realizando e à educação que estão recebendo. A motivação pode ser intrínseca ou externamente imposta a eles (através da pressão dos pais ou da sociedade). De toda forma, o resultado sul-coreano acima da média corrobora a ideia de que na Coreia do Sul é mais forte a visão da educação como promotora de oportunidades para se ter uma boa vida no futuro. 
Outra questão presente no Pisa trata de um indicativo da competitividade do ambiente escolar. Na média da OCDE, 59,2\% dos alunos declararam concordar ou concordar fortemente com a afirmativa "Eu quero ser um dos melhores alunos da minha turma". Nos dois países enfocados neste trabalho, os resultados foram contrastantes: enquanto na Finlândia, em média, 40,8\% dos alunos concordam com a afirmação, na Coreia do Sul o percentual é mais que o dobro: 81,9\% (gráfico 2).

Esse índice traz à tona uma discussão sobre a relevância do ambiente escolar na formação do indivíduo. As interaçôes entre alunos e professores e entre alunos e seus pares exercem grande influência sobre as conquistas, os valores e as motivaçóes dos indivíduos. Nesse contexto, o elevado índice sul-coreano de respostas positivas para a afirmação "Eu quero ser um dos melhores alunos da minha turma" pode ser interpretado de duas formas: como reflexo da motivação dos alunos para enfrentar os desafios que vivenciam e os que estâo por vir, ou como reflexo do ambiente competitivo ao qual estão submetidos.

Remetemos esse resultado também à visão da educação como um bem posicional. Vista por esse ângulo, ainda que seja pelo retorno que será obtido no futuro, mais importa ter uma educaçáo melhor do que a dos demais colegas do que tê-la, per se. Decerto, algum nível de competitividade é benéfico ao processo de aprendizado e mesmo intrínseco à natureza humana. No entanto, em níveis exagerados, a competição pode gerar muita pressão psicológica, a ponto de originar problemas de saúde, psicológicos e comportamentais, tais como estresse, ansiedade e, em casos mais extremos, risco de depressão e propensão ao suicídio.

Desde 2003, a Coreia do Sul ocupa uma das três primeiras colocaçóes em um ranking da OCDE não tão agradável quanto o do Pisa: o de taxas de suicídio. Em 2013, a taxa de suicídio foi de 28,7 para cada 100 mil pessoas, atrás apenas da Lituânia. O relatório anual publicado em 2016 pelo Escritório de Estatísticas da Coreia do Sul também aponta que, desde 2007, a principal causa de morte dos jovens entre 9 e 24 anos é o suicídio. Em 2014, a taxa foi de 7,4 suicídios para cada 100 mil jovens. As preocupaçôes com desempenho escolar e com a educação superior figuram, para $5 \%$ dos sul-coreanos que já tentaram o suicídio, como razão principal para essa tentativa (Choe, 2008). ${ }^{25}$

De modo contrastante, políticas e reformas educacionais da Finlândia foram desenhadas no intuito de promover cooperação. O objetivo é que as atividades escolares sejam tais que estimulem o comportamento criativo e colaborativo dos alunos (Sahlberg, 2010). Nesse sentido, a disseminação da cultura de parcerias e

25. A causa mais frequente foi relacionada a dificuldades econômicas, para cerca de $35,5 \%$ da população. As fontes dos dados mencionado neste parágrafo são: i) OECD Data (disponível em: <https://bit.ly/3944teq>); e ii) Statistics Korea (disponível em: <http://kostat.go.kr>). 
de troca de informaçóes no ambiente escolar finlandês deixa pouco espaço para a competição pelo posto de melhor aluno da turma.

Segundo OECD (2017), os alunos também foram avaliados com relação à tensão que sentem quanto a seu desempenho nas provas e durante os estudos. Ao analisarem afirmaçóes como "Mesmo estando preparado para uma prova, me sinto preocupado" e "Fico muito tenso quando estou estudando", o percentual de alunos finlandeses que responderam que concordam ou concordam fortemente ficou abaixo da média da OCDE ( $48,6 \%$ versus $55,5 \%$ na primeira afirmação e $17,8 \%$ versus $36,6 \%$ na segunda afirmação). Enquanto o percentual de sul-coreanos que concordam ou concordam fortemente posiciona-se sistematicamente acima da média da OCDE. As afirmaçóes, presentes no Pisa, que selecionamos encontram-se listadas no quadro 1 e as comparações entre os resultados finlandeses e coreanos estáo ilustradas no gráfico 3 .

\section{QUADRO 1}

Afirmações relacionadas à ansiedade e pressão escolar

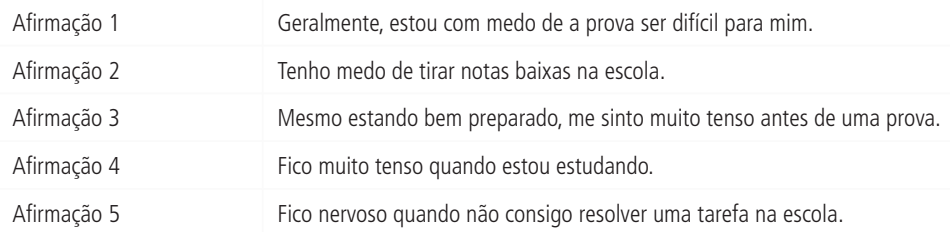

Elaboração dos autores.

\section{GRÁFICO 3}

Percepção dos estudantes quanto à ansiedade e à pressão escolar (Em \%)

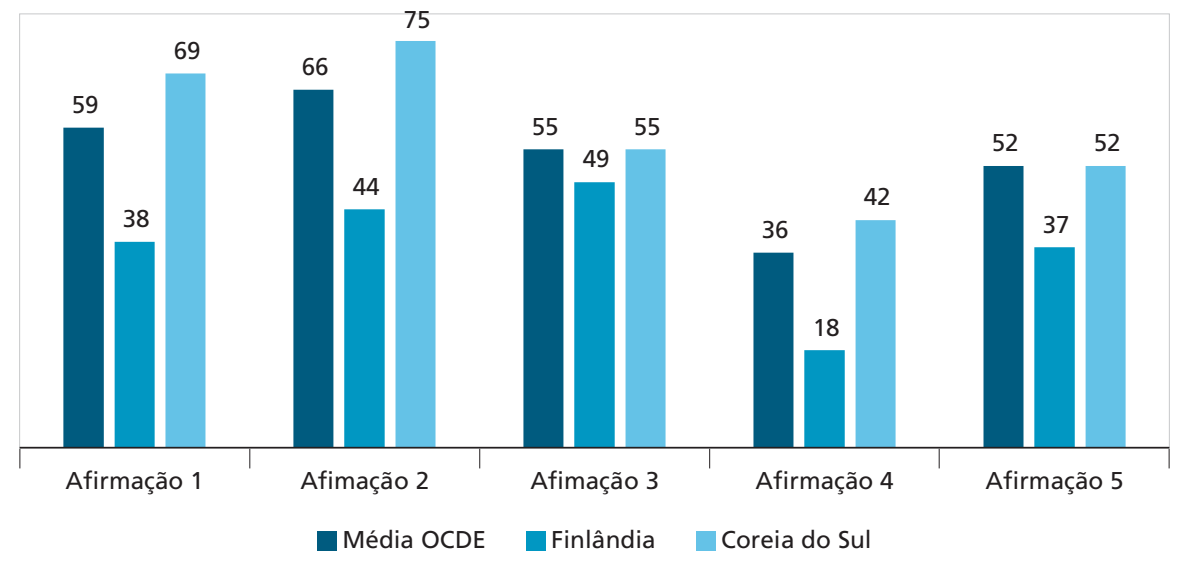


Explicar as origens das tensôes e das ansiedades vivenciadas pelos alunos escapa ao economista, mas psicólogos e pedagogos afirmam que uma das causas para o estresse crônico nos alunos está centrada na preocupação com o desempenho acadêmico e com o processo de admissáo nas universidades (Leonard et al., 2015). Essa afirmação vai ao encontro das circunstâncias sul-coreanas: a pesquisa é realizada com alunos de 15 anos, fase em que a maioria desses jovens está começando a vivenciar o ipsijiok (o inferno do vestibular).

Por outro lado, os alunos finlandeses aparentam ser menos pressionados nas questôes escolares, possivelmente em função da cultura de um ensino mais flexível, sem uma grade de avaliaçóes externas. Esse conceito não faz parte dos princípios que norteiam a educação finlandesa. Os estudantes não são regularmente submetidos a provas padronizadas externas para avaliaçáo de desempenho, o que reflete a confiança e a autonomia aos próprios profissionais.

Não há como dizer que não haja pressão sobre os estudantes finlandeses, sobretudo aqueles do ensino secundário - alguns dos quais enfrentarão processo seletivo para ingressar na universidade. Todavia, o dia a dia na escola é suficiente para identificar alunos com necessidades especiais, que passam a ser tratados de maneira distinta. Ao identificar tais alunos, uma equipe multidisciplinar de profissionais passa a se reunir periodicamente para discutir seu progresso e buscar soluçôes para dirimir seus obstáculos (OECD, 2014). Deste modo, é criado um clima em que os alunos se sentem mais acolhidos do que pressionados.

A rotina dos alunos sul-coreanos do ensino médio, especialmente daqueles que fazem uso de aulas suplementares, é de dedicação integral aos estudos. Baseado nas respostas que os estudantes forneceram no Pisa, na Coreia do Sul, a média de horas de estudo por semana é de 6 horas acima da média dos países da OCDE ( $50 \mathrm{~h}$ versus $44 \mathrm{~h}$ ), ao passo que a média finlandesa é 8 horas abaixo da média da OCDE (36h versus 44h), como podemos observar no gráfico 4.

OECD (2017) cruzou a quantidade de horas que os alunos passam em aulas de matemática, leitura e ciências com as notas obtidas pelos estudantes no exame e encontrou uma correlação positiva para ciências (horas adicionais de estudo implicaram em pontuaçóes mais elevadas) em $75 \%$ dos países analisados. Em matemática, a correlação também foi positiva na maioria dos países, mas consideravelmente mais fraca. Por outro lado, em leitura há uma correlação negativa em quase metade dos países analisados: horas adicionais de estudo implicam em pontuaçóes mais baixas.

No entanto, uma segunda interpretação também é possível. Nesse relatório de Pisa (2015), foi calculada a razão entre a pontuação no exame e a quantidade de horas de estudo, como uma aproximaçáo para medida de eficiência dos sistemas educacionais. Nessa medição, o sistema educacional finlandês encontra-se 
em primeiro lugar entre os países-membro da OCDE, uma vez que os alunos são capazes de atingir maiores notas no exame mesmo com uma menor quantidade de horas de estudo.

GRÁFICO 4

Quantidade de horas de estudo semanal

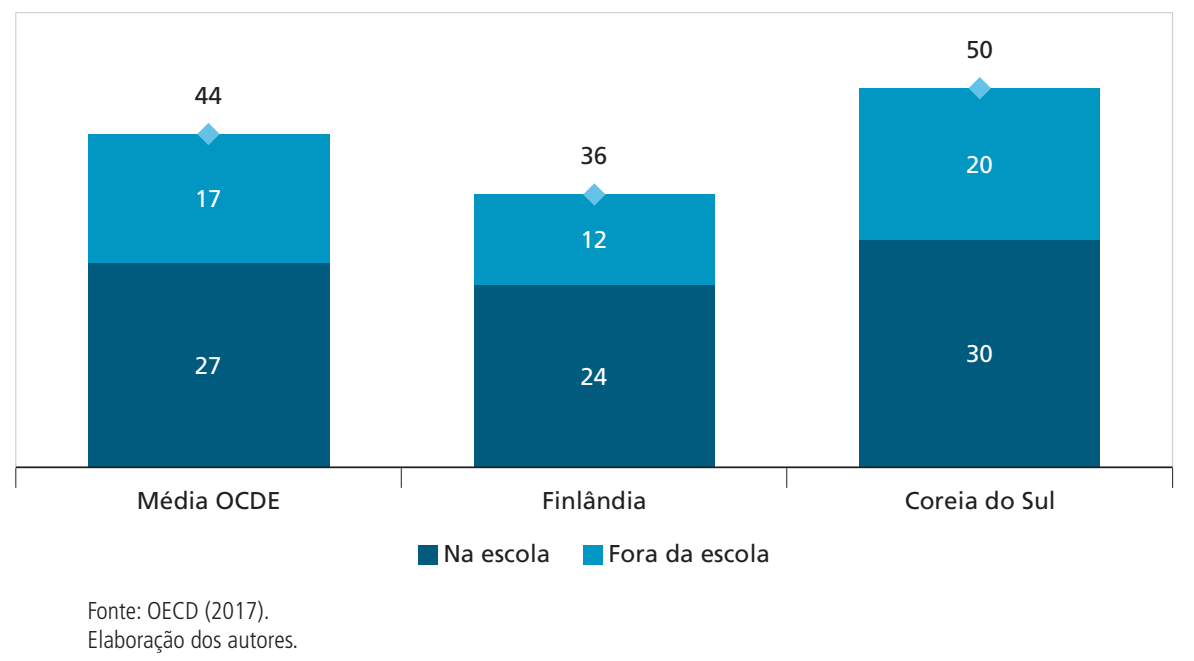

Mais horas de estudo no dia significam redução no tempo livre dos estudantes. O resultado a seguir levou em conta a prática de atividades físicas dos alunos nos dias de aula (gráfico 5).

GRÁFICO 5

Média dos estudantes quanto à prática de atividades físicas (Em \%)

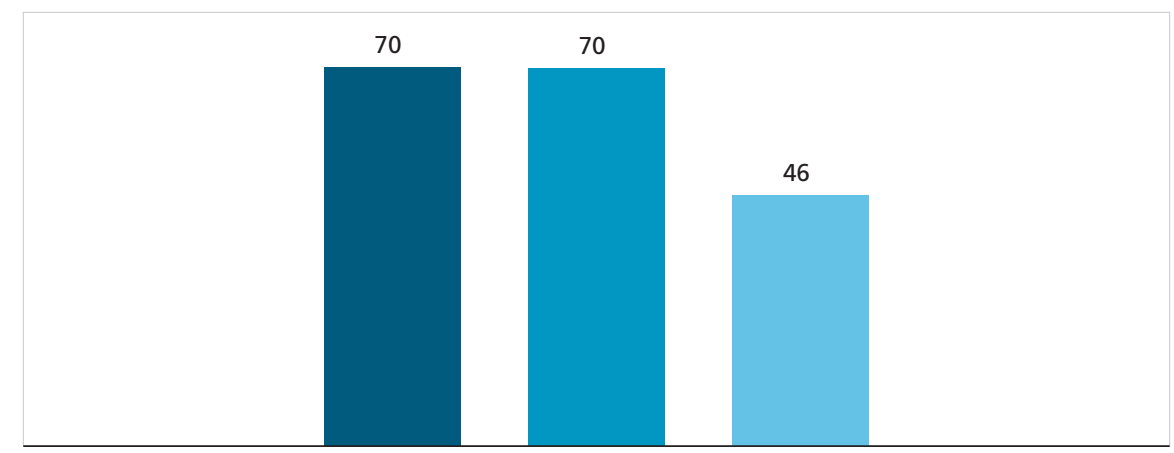

Se exercitam ou praticam esportes antes ou depois da escola

Média OCDE Finlândia Coreia do Sul 
Enquanto a média da OCDE coincide com o resultado finlandês - 70\% dos estudantes praticam atividades físicas antes ou depois da escola - o resultado sul-coreano encontra-se nada menos do que 24 p.p. abaixo. O que coincide com o esperado: com jornada de estudos em três turnos, sobra pouco ou nenhum tempo para cuidar da saúde através da prática de exercícios físicos.

Dos resultados aqui expostos, conclui-se por uma necessidade de atentar para os efeitos que o sistema educacional sul-coreano pode desencadear na saúde dos jovens. A longa jornada de estudos, combinada à pressão por uma boa performance nas provas produz efeitos maléficos à saúde e ao psicológico do aluno, tendo influência direta nas taxas de depressão entre os jovens (Lee e Larson, 2000). Os índices de suicídio, especialmente entre os jovens, são uma preocupação ao governo sul-coreano. Choe (2008) relaciona características do sistema sul-coreano, como aulas suplementares e estudo noturno, ao estresse de origem acadêmica, ao mal-estar subjetivo, às fugas de casa e à propensão ao suicídio. A prática de exercícios físicos poderia servir como um atenuante à situação, no entanto, vimos que, na média, os estudantes dispóem de pouco ou nenhum tempo hábil para tal.

\section{DO COMPORTAMENTO INDIVIDUAL PARA A FORMAÇÃO DA SOCIEDADE}

No início deste trabalho discutiu-se como Sen (2010) relaciona educação e desenvolvimento. Em síntese, além de seu próprio papel constitutivo no desenvolvimento, a educação é capaz de fomentar, além das bases para o crescimento econômico, valores e atitudes individuais que favorecem um comportamento social mais desejável.

A industrialização e a divisão do trabalho modificaram relaçôes sociais, antes baseadas na proximidade das comunidades, para uma nova ordem na qual prevalecem conexôes mais diversas e difusas. Para alguns sociólogos, essa nova ordenaçấo pode tornar-se uma ameaça à consciência coletiva. Nesse sentido, o Estado possui papel importante na promoção da coletividade, da coesão social. Implicitamente, a noção de coesão social carrega um senso de harmonia, compartilhamento de valores e desafios na formação da sociedade. Por este ângulo, a literatura ${ }^{26}$ associa alguns valores a esse conceito, tais como a confiança interpessoal e a tolerância. Outras definições ${ }^{27}$ também fazem uso dos termos reciprocidade e colaboração (Preston e Green, 2003).

26. Como exemplo, Preston e Green (2003) citam as seguintes referências: Almond, G.; Verba, V. The Civic Culture, Princeton: Princeton University Press, 1963; e Putnam, R. Bowling Alone, New York: Simon and Schuster, 2000. 
A partir de análises teóricas e quantitativas, Green et al. (2003) sugerem que desigualdades educacionais e de renda afetam significativamente a coesão social. Nesse sentido, um dos meios pelos quais a educação impacta na coesão social é através da redução das desigualdades. Da mesma forma, segundo OECD (2015), níveis educacionais mais elevados estão associados a diversos resultados sociais positivos. Ademais, as pesquisas compiladas por Feinstein et al. (2008) já haviam encontrado evidências da influência positiva ou negativa da educação do indivíduo em sentimentos e atitudes relevantes na formação da sociedade e no senso de cidadania, tais como o autocontrole, a tolerância com o próximo, o engajamento em trabalho voluntário e o interesse pela participação nas decisóes políticas.

De forma a ilustrar alguns desses sentimentos e comportamentos sociais das populaçóes finlandesa e sul-coreana, também em comparação com a média de outros países, apresentamos aqui alguns dados extraídos da pesquisa internacional Survey of Adult Skills, coordenada pelo Programa para Avaliação Internacional de Competências de Adultos (em inglês, Programme for the International Assessment of Adult Competencies - PIAAC) da OCDE. Dada sua proximidade com os aspectos aqui citados da proposta seniana de desenvolvimento, tais dados serão considerados, neste trabalho, como indicadores aproximados do desenvolvimento como liberdade.

A primeira edição da pesquisa foi aplicada em 24 países da OCDE, entre 2011 e 2012, e entrevistou pessoas de 16 a 65 anos. Entre 2014 e 2015 a pesquisa foi aplicada em mais nove países. O foco dessa pesquisa é mostrar como adultos utilizam o conhecimento obtido e quais benefícios são obtidos por utilizá-los, permitindo que se identifique quais são as habilidades individuais que levam à prosperidade social e econômica. De modo semelhante ao que fizemos na seção 7, colocaremos graficamente os dados finlandeses e coreanos em comparação, visando utiliza-los como indicadores do desenvolvimento, segundo a noçáo que permeia todo este trabalho.

O primeiro resultado relevante trata da percepção dos respondentes da pesquisa quanto a seu próprio estado de saúde. 
GRÁFICO 6

Percepção de boas condições de saúde

(Em \%)

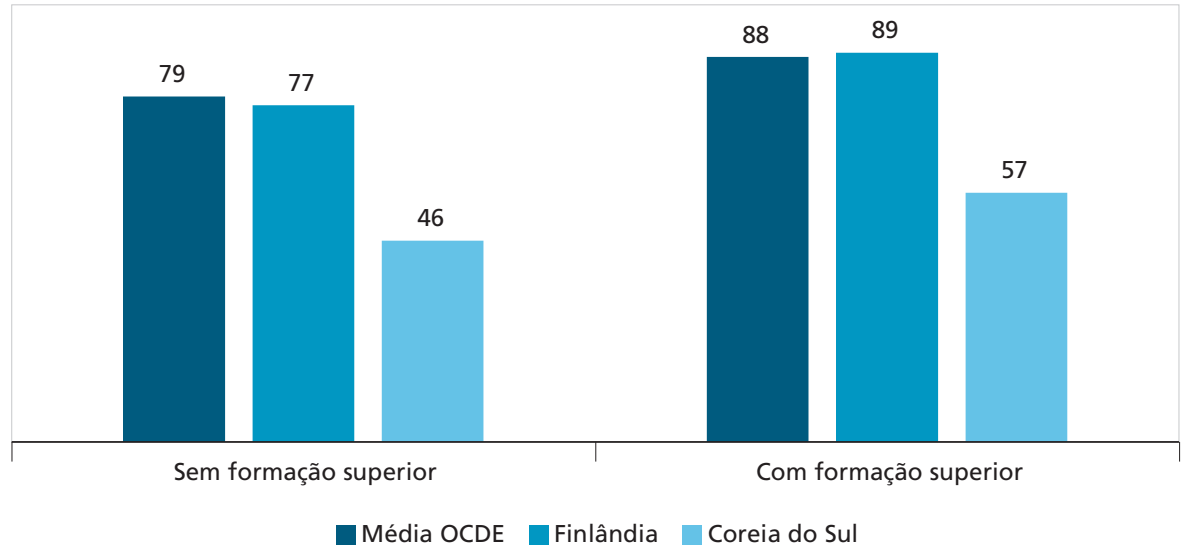

Fonte: OECD (2015).

Elaboração dos autores.

Reportaram estar em boas condiçôes de saúde, em média, 79\% dos respondentes da pesquisa nos países onde a primeira rodada foi aplicada, que não possuem ensino superior. Entre os que possuem nível superior, este percentual aumenta para $88 \%$ (gráfico 6).

As médias finlandesas foram próximas às médias da pesquisa: $77 \%$ dos que não possuem ensino superior remeteram estar em boa saúde, enquanto que $89 \%$ dos que possuem ensino superior deram a mesma resposta. Por sua vez, na Coreia do Sul esse resultado é bastante inferior: menos da metade dos respondentes que não possuem nível superior entendem estar em boas condiçóes de saúde. A parcela é um pouco maior entre os que possuem ensino superior (57\%), mas ainda é distante da média.

Sobre esse ponto, é importante ressaltar que a Coreia do Sul possui um elevado índice de alcoólatras em sua população. De acordo com levantamento feito em 2014 pela Euromonitor, os sul-coreanos são os maiores consumidores de bebida alcoólica entre os 44 países pesquisados. Entre os jovens, cerca de 16,7\% dos alunos do ensino secundário fazem uso de bebidas alcóolicas. ${ }^{28}$

A bebida é uma questão cultural na Coreia do Sul. Como forma de aliviar o estresse de longas jornadas de estudo ou trabalho, o álcool tornou-se parte da rotina diária da população, seja nos momentos de lazer e confraternização, seja em casa.

28. Informações disponíveis em STATISTICS on the Youth - 2016. Statistics Korea ([s.d.]). Disponível em: <https://bit.ly/2XcsR8d>. Acesso em: 7 maio 2017. 
As autoridades sul-coreanas estão cientes do efeito negativo do álcool na saúde da população e do seu custo para a sociedade: segundo estatísticas do Ministério da Saúde e Bem-Estar sul-coreano, as despesas anuais decorrentes do consumo de álcool no país chegam a ultrapassar a marca de US $\$ 20$ bilhóes.

Pôde-se verificar no gráfico 6 que mais da metade da população sul-coreana não se considera em boas condiçóes de saúde, o que pode ter relação com o consumo excessivo de álcool. É possível que jovens que passam a vida escolar pressionados, buscando subterfúgios para aliviar o estresse, podem tornar-se adultos que se ancoram na bebida. Portanto, políticas no sentido de tornar a experiência escolar mais amena poderiam impactar positivamente na reversão destes números.

Aqueles que possuem ensino superior estáo mais otimistas quanto a seus níveis de saúde do que os menos escolarizados, tanto na Finlândia como na Coreia do Sul e na média da OCDE. Esse resultado está em linha com a ideia de Sen (2010), de que as liberdades instrumentais se inter-relacionam e se complementam no propósito de contribuir para que as pessoas vivam mais livremente. Para o autor, tipos distintos de liberdades se vinculam uns aos outros, reforçando sua importância conjunta. É o caso da educação e da saúde. Indivíduos mais educados estão mais propensos a levar uma vida saudável, dado que estão expostos a um volume maior de informações.

Um segundo ponto abordado na pesquisa do PIAAC, mais próximo aos conceitos de cidadania e coesáo social, foi a propensão ao voluntariado. O voluntariado é uma atividade que mostra que as pessoas podem ser movidas por alguma força interior além do autointeresse, que prevalece no mecanismo das trocas do mercado. ${ }^{29}$ Açóes desse tipo demonstram valores sociais muito mais amplos, compostos por um senso de justiça importante para a visão de desenvolvimento aqui adotada.

$\mathrm{Na}$ média dos países pesquisados, $18 \%$ dos respondentes sem formação superior disseram realizar atividades voluntárias ao menos uma vez por mês, e 23\% dos que possuem ensino superior deram a mesma resposta. Em todos os países participantes da pesquisa, houve uma relação positiva entre a formação escolar e a propensão ao voluntariado.

$\mathrm{Na}$ Finlândia, os percentuais são próximos à média: responderam afirmativamente essa questáo $19 \%$ dos que não possuem ensino superior e $25 \%$ dos que possuem ensino superior (gráfico 7). As médias sul-coreanas encontram-se em patamares inferiores: $12 \%$ dos que não possuem ensino superior responderam afirmativamente essa questáo, 1 p.p. abaixo do verificado entre os que possuem ensino superior, o que indica que há margem para que o país possa evoluir em mais esse quesito.

29. Cabe lembrar que Sen (2010) destaca que nas próprias trocas de mercado podem existir um comportamento benevolente. Ainda que não premeditado, é possível que o indivíduo preveja que suas ações terão impacto positivo na vida das pessoas, contribuindo para uma mudança social. 0 autor se refere a essa questão como consequências impremeditadas. 
GRÁFICO 7

Propensão ao voluntariado

(Em \%)

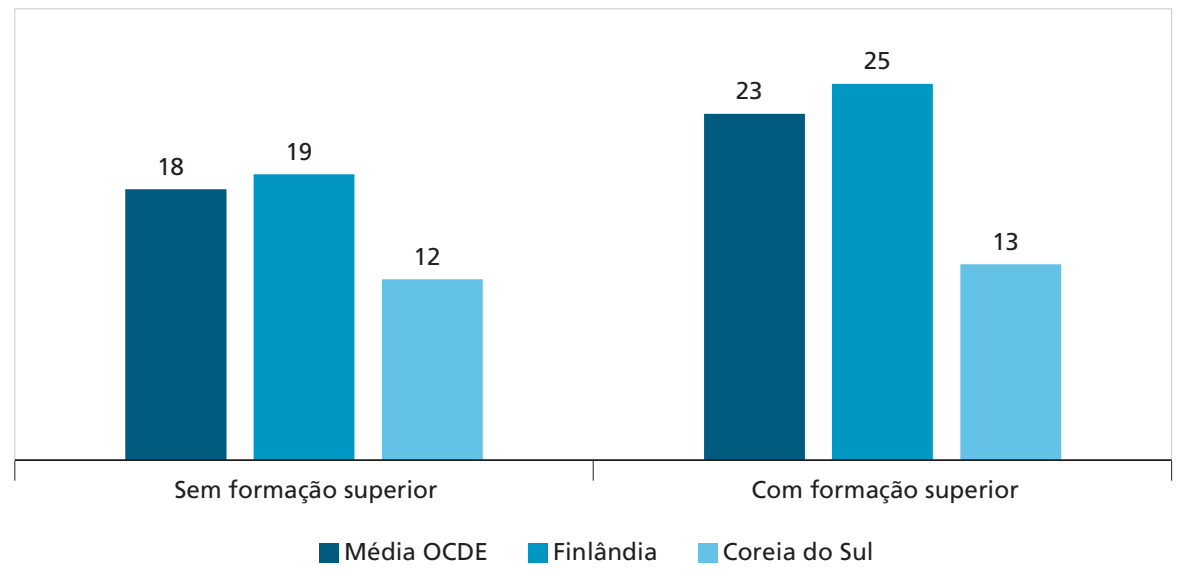

Fonte: OECD (2015).

Elaboração dos autores.

Adicionalmente, a confiança interpessoal da população participante da pesquisa também foi avaliada. O gráfico 8 mostra que, em média, a proporção de adultos que responderam que confiam nos demais foi de $18 \%$ entre os que não possuem ensino superior e de $30 \%$ entre os que possuem.

GRÁFICO 8

Confiança interpessoal

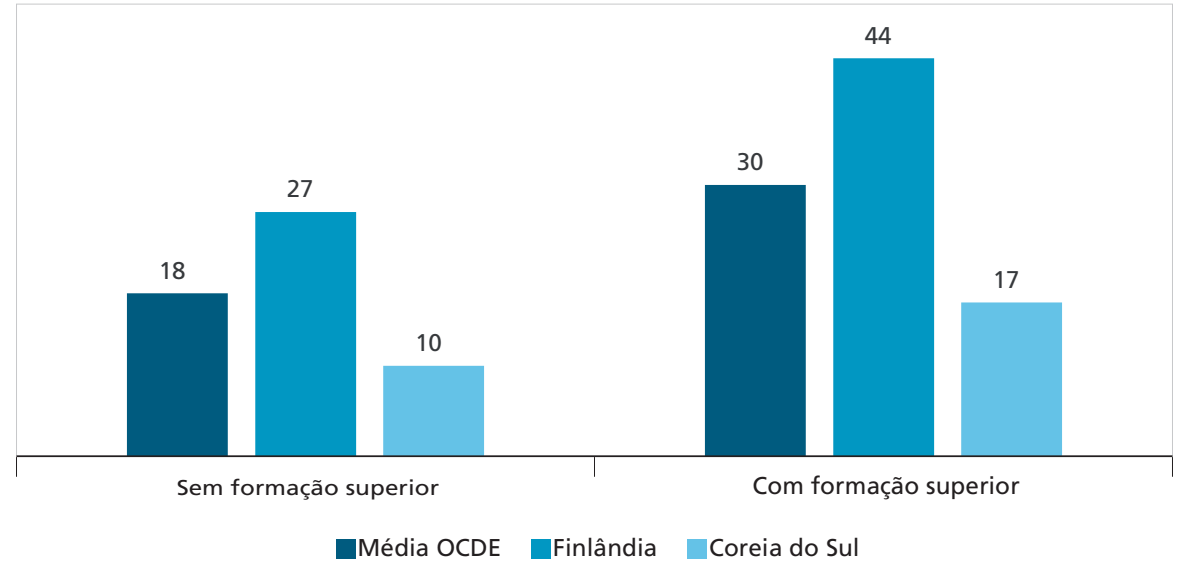

Fonte: OECD (2015).

Elaboração dos autores. 
Os percentuais finlandeses foram bem mais elevados nesta questáo: $27 \%$ dos que não possuem ensino superior responderam positivamente, enquanto que $44 \%$ dos que possuem ensino superior também o fizeram. Na Coreia do Sul, os números são novamente abaixo da média: $10 \%$ entre os que não possuem ensino superior e $17 \%$ entre os que possuem ensino superior.

A confiança interpessoal é um dos valores relevantes que geralmente são associados à coesão social. A despeito de todo o debate que envolve a definição do conceito de confiança, o sentido entendido pelos respondentes deste tipo de pergunta aparenta ser generalizado. Acredita-se que os indivíduos submetidos à pesquisa respondem essa pergunta pensando se há confiança nas pessoas não tão próximas quanto familiares e amigos, mas com as quais o sujeito tem contato esporadicamente na sociedade moderna - colegas de trabalho, cidadãos em geral (Preston e Green, 2003).

Embora essa seja uma percepção subjetiva, sensível ao momento em que o respondente é avaliado e às circunstâncias às quais ele está submetido, Preston e Green (2003) comentam que existe uma certa consistência entre os níveis de resposta a esta pergunta em diferentes pesquisas, atribuindo maior robustez aos resultados das pesquisas.

Para Sen (2010), a confiança é um pressuposto básico para as interações sociais. Numa sociedade desenvolvida, os indivíduos esperam certo grau de sinceridade ao lidar uns com os outros; é preciso que haja garantias de transparência, caso contrário a vida dos cidadãos pode ser afetada negativamente. Segundo o autor, as garantias de transparência também são consideradas como um tipo de liberdade instrumental, tendo em vista sua importância para inibir comportamentos corruptos e transaçóes ilícitas.

Os dados analisados por Preston e Green (2003) não apresentaram evidências da correlação entre o nível educacional das pessoas e os níveis de confiança dos países. Contudo, existe uma forte correlação entre a distribuição dos resultados educacionais e a confiança, indicando que o assunto requer pesquisas mais atentas. O gráfico 8 mostra claramente que indivíduos que possuem nível superior estão mais propensos a confiar nos outros do que aqueles que possuem escolaridade mais baixa. Decerto, há outros fatores que influenciam o nível de confiança das pessoas, portanto é conveniente desenvolver novas pesquisas para descobrir se a educação é um deles.

Por fim, aos respondentes foi perguntado se eles acreditam ter voz ativa no governo (gráfico 9). Em média, 30\% dos que não possuem ensino superior disseram que sim, índice que se eleva em 13 p.p. entre os que possuem ensino superior. Os sul-coreanos que não possuem ensino superior acompanham a média e os que possuem ensino superior também ficam bem próximos à média. Por outro lado, os 
finlandeses parecem ser mais otimistas: $42 \%$ dos que não possuem ensino superior acreditam ter voz no governo, enquanto que mais da metade da população que possui ensino superior tem essa percepção.

GRÁFICO 9

Percepção de ter voz no governo

(Em \%)

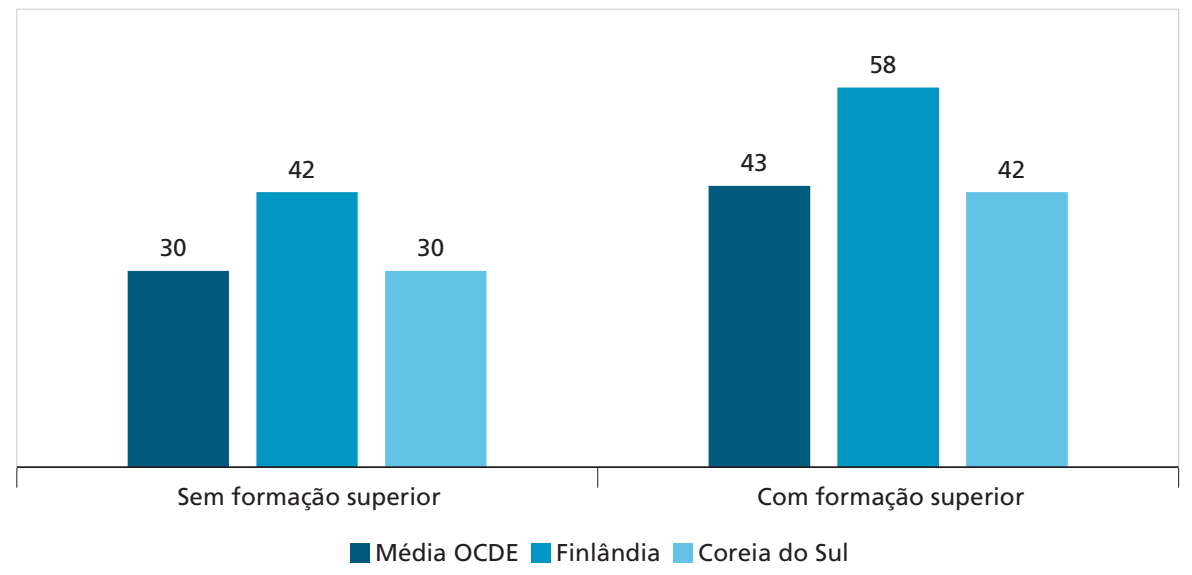

Fonte: OECD (2015).

Elaboração dos autores.

Sen (2010) afirma que, para o desenvolvimento, tão relevante quanto a satisfação das necessidades econômicas é a defesa da democracia. Adicionalmente, esses dois tipos de liberdades se relacionam de maneira não somente instrumental (garantir a liberdade política como forma de estímulo à prosperidade econômica), mas também constitutiva. Os direitos políticos fazem parte do conjunto de capacitaçôes básicas dos indivíduos. A participação social em debates públicos é fundamental na conceituação aqui adotada.

Por muitos anos vigorou na Coreia do Sul um regime político autoritário, no qual prevaleciam todas as restriçóes inerentes a este tipo de regime. De fato, mostrou-se aqui que foi durante o período ditatorial que o crescimento econômico se fez mais vigoroso. Entretanto, se para muitos ${ }^{30}$ ainda parecia haver uma dicotomia entre garantir direitos civis e políticos e atender as necessidades econômicas, Sen (2010) afirma haver pouca evidência empírica que sustente uma influência direta do autoritarismo no desenvolvimento econômico. Essa relação é suscetível às circunstâncias gerais às quais cada país está submetido. $\mathrm{Na}$ Coreia do Sul, por exemplo, foram vários os fatores que levaram o país às elevadas taxas de crescimento

30. Segundo Sen (2010), esse foi um pensamento bastante defendido na // Conferência Internacional de Direitos Humanos, realizada em Viena, em 1993. 
observadas: reforma agrária, qualificação da população, investimentos feitos ou incentivados pelo Estado etc.

Embora o autoritarismo já tenha sido formalmente superado na jovem democracia sul-coreana, há quem diga que a cultura oriental ainda preza por valores como disciplina e a manutenção da ordem, de tal forma que os direitos dos cidadãos estejam subordinados e condicionados à proteção de necessidades superiores, comprometendo, portanto, a valorização da liberdade política e civil. Apesar de reconhecer a existência de tais valores nas sociedades asiáticas, Sen (2010) preocupa-se em difundir a ideia de superficialidade nesse discurso cultural. Para o autor, a tradição asiática é muito mais variada e rica do que o discurso comum, sendo possível encontrar elementos semelhantes às ideias do Ocidente.

De todo modo, não se deve perder de vista que não só o crescimento econômico compóe o desenvolvimento, mas a qualidade de vida da população também deve ser julgada. E, neste ponto, a democracia é particularmente importante na medida em que permite que as pessoas sejam ouvidas quanto às suas necessidades e reivindiquem açóes do governo quanto ao que consideram restringir suas liberdades. $\mathrm{Na}$ prática, essa reivindicação se manifesta pelo poder de voto da população, pelo poder de cobrar dos que foram eleitos e os representam e, eventualmente, de se opor à condução da política e protestar (Sen, 2010).

A Survey of Adult Skills mostrou que, na média dos países analisados, menos de um terço da população sem ensino superior acredita ter oportunidade de expressar suas opiniōes políticas e de ser ouvida. Resultado preocupante, uma vez que essas pessoas entendem que sua capacidade de participação política e social, componente vital para a definição de desenvolvimento aqui adotada, está comprometida.

De acordo com Sen (2010), a educação é uma facilidade importante para a promoção da participação política das pessoas. Essa promoção se dá na medida em que os indivíduos mais bem informados são capazes de comunicar-se melhor, além de ter maior conhecimento de seus direitos e dos meios através dos quais é possível reivindicá-los.

\section{CONCLUSÕES}

Foi através de transformaçôes de grande porte que Finlândia e Coreia do Sul abandonaram, em pouco tempo, o status de países subdesenvolvidos e realizaram o chamado catching up. Na busca pelos pilares que sustentaram essas transformaçóes, a mão de obra qualificada, presente nos dois países, destaca-se como componente substancial para permitir a adoção das novas estratégias. A educação foi prioritária aos governos dos dois países ao longo da segunda metade do século XX, e continuam a sê-lo no início deste século. 
Os sistemas educacionais desses países são produto de uma construção ao longo do tempo, calcados em noçóes e objetivos diferentes. Enquanto na Coreia do Sul a visão da educação esteve, historicamente, ligada à sua função como capital humano, na Finlândia a motivação encontra raízes no welfare state, com propósitos mais amplos, como um meio de redistribuiçâo de renda, por exemplo. É natural que sistemas tão distintos em suas concepçôes e suas gestóes, quando comparados, provoquem efeitos desejados ou indesejados, em maior ou menor grau, nos alunos e na sociedade. A edição do Pisa de 2015, que pela primeira vez apresentou avaliaçóes relacionadas ao bem-estar e à qualidade de vida dos alunos, revela consideraçôes importantes acerca do assunto.

Em primeiro lugar, o grau de equidade dos sistemas pôde ser inferido a partir da diferença na pontuação média do exame de ciências do Pisa entre os alunos de escolas menos favorecidas socioeconomicamente e aqueles matriculados em escolas mais favorecidas. Na Finlândia, essa diferença foi, em pontos, menos da metade do que na Coreia do Sul. Dado o reconhecimento de que um ensino de boa qualidade influencia diretamente nas oportunidades que o indivíduo terá no futuro, esse tipo de sistema menos equânime prejudica o potencial componente redistributivo da educação, perpetuando eventuais atrasos daqueles menos providos de renda.

Adicionalmente, nessa edição do Pisa, os estudantes foram questionados quanto a suas percepçóes sobre seus sentimentos como satisfação com a vida, motivação, competição, ansiedade e a tensão provocada pelos assuntos escolares, além de seus hábitos de estudo e de exercícios físicos.

Os dados mostram que estudantes finlandeses se saíram acima da média dos demais países da OCDE, em termos de satisfaçấo com a vida, e abaixo da média da OCDE em afirmaçóes relacionadas à possível ansiedade e à pressão vivenciada no ambiente escolar, ao passo que o resultado sul-coreano foi o contrário. Ao mesmo tempo, pôde-se verificar que estudantes sul-coreanos são mais competitivos que a média da OCDE e dedicam mais horas semanais aos estudos (formal e suplementar).

É importante ressaltar que, de acordo com as análises de Pisa (2015), não há indícios de uma relação forte entre o desempenho dos alunos no exame e a satisfação reportada, o que ratifica a ideia de que sistemas educacionais aparentemente bem-sucedidos nem sempre estão atrelados à promoção das liberdades almejadas pelos indivíduos.

Da mesma forma, fazendo uso de uma outra série de resultados extraídos do PIAAC, também da OCDE, buscamos verificar, por meio da percepção de vida das pessoas de 16 a 65 anos, aproximaçóes das ideias preconizadas pela perspectiva do desenvolvimento como liberdade. Foram apresentados resultados relacionados 
à sua percepção de saúde, de confiança nos demais, de ter voz no governo e sua propensão ao voluntariado. Esses foram aqui considerados como indicativos de coesão social, das garantias de transparência e da noção de cidadania participativa que permeia a conceituação de Sen.

Os resultados mostram que a Coreia do Sul se encontra em patamares muito abaixo da média dos países da OCDE em quase todos os pontos analisados na seção 8 deste trabalho. Enquanto isso, a Finlândia figura próxima ou acima da média. A partir da análise desses dados, é possível perceber que há margem para melhora nos indicadores sul-coreanos, e, como consequência da noção aqui adotada, no nível de desenvolvimento desse país. A educação poderia contribuir para essa melhora, desde que seja entendida como promotora de bem-estar tal qual é vista na perspectiva mais ampla de Sen.

Por outro lado, a eficiência do sistema educacional finlandês pode ser considerada bem-sucedida na medida em que atende às demandas de três atores: i) o governo que, motivado por seus objetivos de desenvolvimento, intensificados com a manutenção de um forte welfare state, pode contar com uma população mais educada, politicamente participativa e com maiores traços de cidadania; ii) o setor privado, que passou a buscar empregados com excelência não só nas disciplinas formais, mas que também possuíssem características de criatividade, trabalho em equipe e solução de problemas; e iii) a própria população, que passou a aspirar maiores oportunidades de educação (OECD, 2014).

Conclui-se, portanto, que, apesar de ambos os sistemas educacionais serem bem-sucedidos nos resultados relacionados a habilidades e conhecimentos tradicionais, os elementos expostos neste artigo relacionados ao sistema educacional finlandês estão mais próximos de contribuir positivamente para os indicadores aqui utilizados como aproximaçáo de desenvolvimento visando à liberdade; ao passo que, em relação aos elementos destacados do sistema educacional sul-coreano, não parecer haver a mesma eficácia na produção dos efeitos desejados nessa perspectiva.

Cabe reforçar que, no que tange à educação, não há uma solução única que seja ideal para aplicação em naçóes distintas, por este motivo, advogar em favor de um sistema ou de outro não é proveitoso. Mais importante de se registrar são as experiências positivas que podem ser extraídas dos sistemas em estudo. Entretanto, buscou-se assinalar neste trabalho que as análises das liçóes aprendidas com países de alto desempenho, em exames como o Pisa, devem ser tomadas com cautela: as pontuaçóes elevadas podem esconder aspectos indesejáveis ao comportamento individual e possuem impacto relevante na formação da sociedade. 


\section{REFERÊNCIAS}

ARBIX, G.; FERRAZ, J. Finlândia: competitividade e economia do conhecimento. In: CARDOSO JR et al. (Orgs.) Trajetórias recentes de desenvolvimento: estudos de experiências internacionais selecionada. Brasília: Ipea, 2009.

BECKER, G. Human capital: a theoretical and empirical analysis, with special reference to education. New York: Columbia University Press, 1964.

BRAY, M.; LYKINS, C. Shadow Education: private supplementary tutoring and its implications for policy makers in Asia. Philippines: Asian Development Bank, 2012. (CERC Monograph Series in Comparative and International Education and Development, n. 9).

CHOE, J. The impact of supplemental classes and night self-study in school on academic stress, subjective well-being, runaway from home, and suicidal impulses among high school students. Korean Journal of Social Issues, v. 9, n. 2, p. 211 232, Oct. 2008.

DAHLMAN, C.; ROUTTI, J.; YLÄ-ANTTILA, P. Finland as a Knowledge Economy: elements of success and lessons learned. Washington, D. C.: World Bank, 2006. (WBI Development Studies).

ECCLES, J. et al. Negative Effects of Traditional Middle Schools on Students' Motivation. The Elementary School Journal, v. 93, n. 5, p. 553-574, May 1993.

FEINSTEIN, L. et al. (Eds.). The social and personal benefits of learning: a summary of key research findings. London: Institute of Education, Centre for Research on the Wider Benefits of Learning, 2008.

GALA, P.; ROCHA, I.; MAGACHO, G. The structuralist revenge: economic complexity as an important dimension to evaluate growth and development. Sáo Paulo: FGV EESP, Dez. 2016. (Texto para Discussão, n. 436).

GREEN, A. et al. Education, equity and social cohesion: a distributional model. London: Centre for Research on the Wider Benefits of Learning, Mar. 2003. (Wider Benefits of Learning Research Report, n. 7).

HAFFNER, J.; OLIVEIRA, A. Inovação tecnológica e desenvolvimento: o caso da Finlândia. Análise Econômica, Porto Alegre, v. 32, n. 62, p. 225-250, set. 2014. HIDALGO, C.; HAUSMANN, R. The building blocks of economic complexity. Proceedings of the National Academy of Sciences of the United States of America (PNAS), Cambridge, v. 106, n. 26, p. 10570-10575, Jun. 2009.

HIRSCHMAN, A. The rise and decline of development economics. In: Essays in trespassing: economics to politics and beyond. Cambridge: Cambridge University Press, 1981. 
KIM, J. Education Policies and Reform in South Korea. In: WORLD BANK. Secondary Education in Africa: strategies for renewal. Mauritius: Huma, 2002. p. 29-39.

LEE, C. Administration and funding of the education system in Korea. SNU Journal of Education Research, Seoul, v. 5, p. 11-53, 1995.

LEE, J. Main reform on higher education systems in Korea. Revista Electrónica de Investigación Educativa, Seoul, v. 2, n. 2, p. 62-76, Oct. 2000.

LEE, M. Korean adolescents "examination hell" and their use of free time. New Directions for Child and Adolescent Development, v. 2003, n. 99. p. 9-21, Mar. 2003.

LEE, M.; LARSON, R. The Korean "Examination Hell”: Long hours of studying, distress, and depression. Journal of Youth and Adolescence, v. 29, n. 2, p. 249 271, Apr. 2000.

LEE, W. Economic growth and human development in the Republic of Korea, 1945-1992. United Nations Development Program: Human Development Reports, 1997. (Occasional Papers, n. 24).

LEONARD, R. et al. A multi-method exploratory study of stress, coping, and substance use among high school youth in private schools. Frontiers in Psychology, v. 6, n. 1028, 2015.

LIM, P. Path Dependence in action: the adoption and persistence of the Korean Model of Economic Development. World Bank, 2003.

MOOS, R. The Social Climate Scales: an overview. Palo Alto, CA: Consulting Psychologists Press, 1974.

OECD - ORGANIZATION FOR ECONOMIC CO-OPERATION AND DEVELOPMENT. Strong performers and successful reformers: Korea. In: Lessons from PISA for Korea, Strong Performers and Successful Reformers in Education. OECD Publishing, 2014.

Education at a Glance 2015: OECD Indicators. OECD Publishing, 2015. . Pisa 2015 Results (vol III): Students' well-being. Paris: OECD Publishing, 2017.

ORNSTON, D.; REHN, O. An old consensus in the "new" economy? Institutional adaptation, technological innovation and economic restructuring in Finland. In: ZYSMAN, J.; NEWMAN, A. (Eds.). How revolutionary was the digital revolution? Stanford: Stanford University Press, 2006. cap. 4. 
PARVIAINEN, J. As florestas e a silvicultura na Finlândia. Brasília: Embaixada da Finlândia, 2010. Disponível em: <https://bit.ly/3fCiDqe>. Acesso em: 25 mar. 2016.

PRESTON, J.; GREEN, A. The macrosocial benefits of education, training and skills in comparative. London: Centre for Research on the Wider Benefits of Learning, 2003. (Wider Benefits of Learning Research Report, n. 9).

RITZEN, J.; EASTERLY, W.; WOOLCOCK, M. On "Good” Politicians and "Bad Policies": Social Cohesion, Institutions and Growth. In: CONGRESSO IIPF, 56., Sevilla, Espańa, 2000. Anais... Sevilla: IIPF, 2000. (Notas principais).

ROBERTS, B. Personality Development and Organizational Behavior. In: STAW, B. (Ed.). Research on Organizational Behavior. Oxford: Elsevier Science; JAI Press, 2006. p. 1-41.

SAHLBERG. P. Education policies for raising student learning - the Finnish approach. Journal of Education Policy, Washington, v. 22, n. 2, p. 147-171, 2007.

. Educational change in Finland. In: HARGREAVES et al. (Eds.).

Springer International Handbooks of Education - Second International Handbook of Educational Change. New York: Springer Science \& Business Media, 2010. p. 323-348.

SCHULTZ, T. Capital formation by education. The Journal of Political Economy, v. 68, n. 6, p. 571-583, 1960.

SEN, A. Development: which way now? The Economic Journal, v. 93, n. 372, p. 745-762, Dec. 1983.

. Development as Capability Expansion. Journal of Development Planning, n.19, p. 41-58, 1989.

. Capital humano y capacidad humana. Cuadernos de Economía, v. 17, n. 29, p. 67-72, 1998.

Desenvolvimento como liberdade. 1. ed. São Paulo: Companhia das Letras, 2010.

SETH, M. Education Fever: society, politics, and the pursuit of schooling in South Korea. Honolulu: University of Hawaii Press, 2002.

A concise history of modern Korea: from the late nineteenth century to the present. United Kingdom: Rowman \& Littlefield Publishers Inc., 2010.

SOSA, A. et al. Prevalence, distribution, and impact of mild cognitive impairment in Latin America, China and India: a 10/66 population-based study. PLoS Medicine, v. 9, p. e1001170, 2012. 
TIÇASTOKESKUS, Official Statistics of Finland (OSF): educational structure of population. Tiçastokeskus, [s.d.]. Disponível em: <https://bit.ly/3mt0vSn>. Acesso em: 1 ago. 2016.

VARIAN, H. Microeconomia: uma abordagem moderna. 7. ed. Rio de Janeiro: Campus, 2006.

WALKER, M.; UNTERHALTER, E. The capability approach: its potential for work in education. In: Amartya Sen's capability approach and social justice in education. New York: Palgrave Macmillan, 2007.

WORLD BANK. Korea as a Knowledge Economy: evolutionary process and lessons learned. Washington, D.C.: The World Bank, 2006.

. The World Bank Open Data. World Bank, [s.d.]. Disponível em: <https://bit.ly/3nbsG7L >. Acesso em: 20 jun. 2016.

YOON, K. The change and structure of Korean educational policy in History. Italian Journal of Sociology of Education, Padova, v. 6, n. 2, p. 173-200, Jun. 2014.

Data da submissão: $3 / 6 / 2018$

Primeira decisão editorial em: 2/1/2019

Última versão recebida em: 29/1/2019

Aprovação final em: 18/2/2019 


\section{Ipea - Instituto de Pesquisa Econômica Aplicada}

\section{EDITORIAL}

\section{Chefe do Editorial}

Reginaldo da Silva Domingos

\section{Assistentes da Chefia}

Rafael Augusto Ferreira Cardoso

Samuel Elias de Souza

\section{Supervisão}

Camilla de Miranda Mariath Gomes

Everson da Silva Moura

\section{Revisão}

Amanda Ramos Marques

Ana Clara Escórcio Xavier

Clícia Silveira Rodrigues

Idalina Barbara de Castro

Luiz Gustavo Campos de Araújo Souza

Olavo Mesquita de Carvalho

Regina Marta de Aguiar

Hellen Pereira de Oliveira Fonseca (estagiária)

Ingrid Verena Sampaio Cerqueira Sodré (estagiária)

\section{Editoração}

Aeromilson Trajano de Mesquita

Cristiano Ferreira de Araújo

Danilo Leite de Macedo Tavares

Herllyson da Silva Souza

Jeovah Herculano Szervinsk Junior

Leonardo Hideki Higa

\section{Capa}

Luís Cláudio Cardoso da Silva

\section{Projeto Gráfico}

Renato Rodrigues Bueno

The manuscripts in languages other than Portuguese published herein have not been proofread.

\section{Livraria Ipea}

SBS - Quadra 1 - Bloco J - Ed. BNDES, Térreo

70076-900 - Brasília - DF

Tel.: (61) 2026-5336

Correio eletrônico: livraria@ipea.gov.br 

Composto em adobe garamond pro 11/13,2 (texto) Frutiger 67 bold condensed (títulos, gráficos e tabelas) Brasília-DF 